\title{
Controlled Drug Substance Use in West Virginia: An investigation into Doctor Shopping, Pharmacy Shopping, And Prescription Histories
}

\author{
Gretchen L. Peirce \\ West Virginia University
}

Follow this and additional works at: https://researchrepository.wvu.edu/etd

\author{
Recommended Citation \\ Peirce, Gretchen L., "Controlled Drug Substance Use in West Virginia: An investigation into Doctor \\ Shopping, Pharmacy Shopping, And Prescription Histories" (2011). Graduate Theses, Dissertations, and \\ Problem Reports. 4766. \\ https://researchrepository.wvu.edu/etd/4766
}

This Thesis is protected by copyright and/or related rights. It has been brought to you by the The Research Repository @ WVU with permission from the rights-holder(s). You are free to use this Thesis in any way that is permitted by the copyright and related rights legislation that applies to your use. For other uses you must obtain permission from the rights-holder(s) directly, unless additional rights are indicated by a Creative Commons license in the record and/ or on the work itself. This Thesis has been accepted for inclusion in WVU Graduate Theses, Dissertations, and Problem Reports collection by an authorized administrator of The Research Repository @ WVU. For more information, please contact researchrepository@mail.wvu.edu. 
Controlled Drug Substance Use in West Virginia: An investigation into Doctor Shopping, Pharmacy Shopping, And Prescription Histories

Gretchen L. Peirce

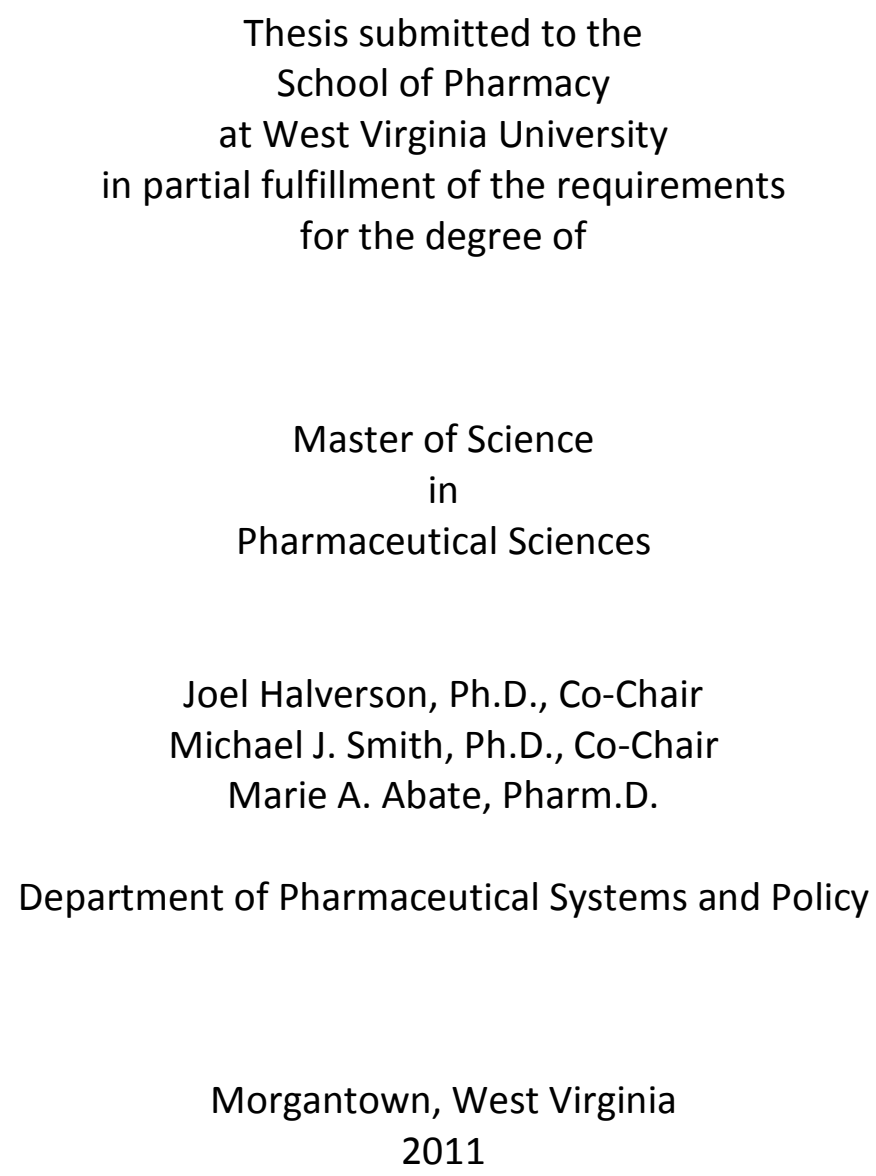

2011

Keywords: Doctor Shopping, Pharmacy Shopping, Controlled Drug Substances, Prescription monitoring programs, Drug-induced/related death, Forensic Drug Database, West Virginia Copyright 2011 Gretchen L. Peirce 


\begin{abstract}
Controlled Drug Substance Use in West Virginia: An investigation into Doctor Shopping, Pharmacy Shopping, And Prescription Histories

Gretchen L. Peirce
\end{abstract}

One objective was to compare the proportion of doctor and pharmacy shoppers between living and deceased users of controlled drug substances (CDS) in West Virginia. A second objective was to identify factors that predict the odds a subject is classified as a shopper. A third objective was to determine factors that predict the odds of dying from CDS use. A final objective was to identify factors that predict the odds of deceased subjects not having verified prescriptions for CDS detected upon autopsy.

A secondary data research study was conducted. The Controlled Drug Substance Monitoring Program and the Forensic Drug Database were used to identify subjects who were 18 years or older and used Schedule II-IV controlled drug substances in the state of West Virginia from July, 1, 2005 to December 31, 2007. Bivariate analyses were used to compare living and deceased subjects for both doctor shopping and pharmacy shopping. Logistic regression was conducted to predict the odds of doctor shopping, pharmacy shopping, and of dying related to CDS use. Bivariate analyses were used to compare decedents with versus without verified prescriptions for CDS detected upon autopsy. Logistic regression was conducted to predict the odds that a decedent did not have verified prescriptions for all CDS detected upon autopsy.

Approximately $25.36 \%$ of deceased subjects and $3.61 \%$ of living subjects were doctor shoppers. Approximately $17.91 \%$ of deceased subjects and $1.31 \%$ of living subjects were pharmacy shoppers. Furthermore, 7,778 subjects were considered both doctor and pharmacy shoppers $(20.31 \%$ of doctor shoppers were also pharmacy shoppers, and $55.83 \%$ of pharmacy shoppers were also doctor shoppers). Age, number of different CDS dispensed, number of prescriptions dispensed, and number of pharmacies visited significantly predicted the odds of being classified as a doctor shopper. Life status, age, number of different CDS dispensed, number of prescriptions dispensed, and number of doctors visited significantly predicted the odds of being classified as a pharmacy shopper. Age, number of different CDS dispensed, number of prescriptions dispensed, and number of pharmacies visited significantly predicted the odds of dying. Approximately $30 \%$ of decedents had a verified prescription for all their CDS detected upon autopsy. Age, number of different CDS at autopsy, and gender significantly predicted the odds of being classified as not having verified prescriptions for all CDS detected upon autopsy.

In conclusion, there is evidence of doctor shopping and pharmacy shopping for controlled drug substances in West Virginia. Interventions by healthcare professionals are important because only a third of decedents had a verifiable prescription for all their CDS detected upon autopsy. Pharmacists as well as physicians may rely on a prescription monitoring program to identify shoppers. Healthcare professionals should consider integrating prescription monitoring program information during delivery of care, and evaluate its impact in preventing drug-induced and drug-related deaths. 


\section{Table of Contents}

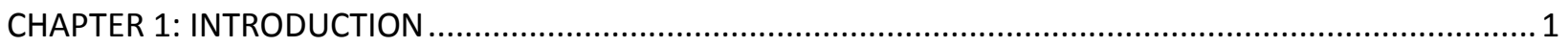

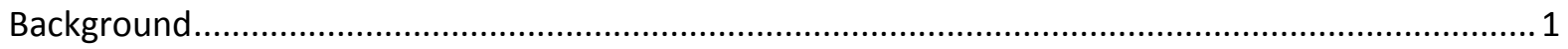

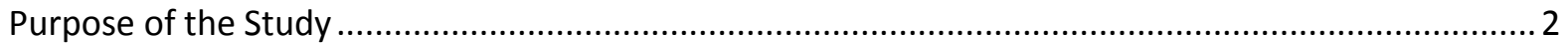

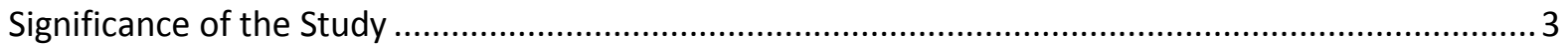

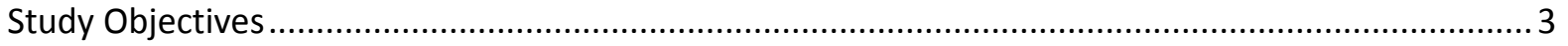

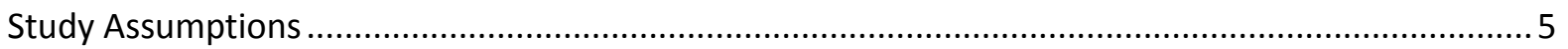

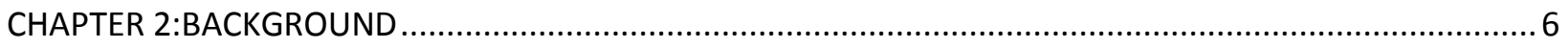

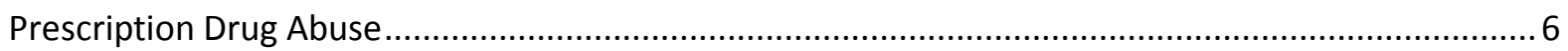

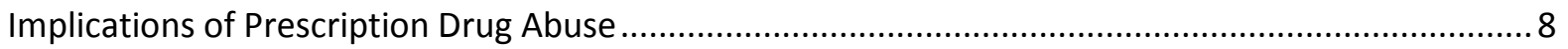

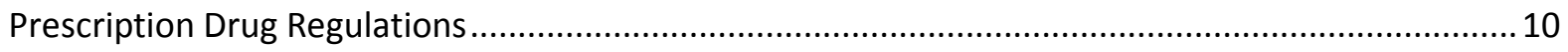

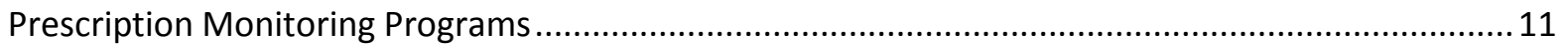

Means of Obtaining Prescription Drugs - Diversion .............................................................. 14

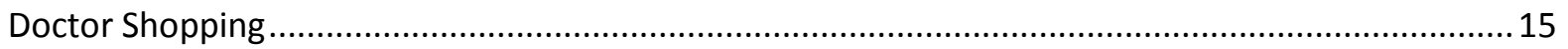

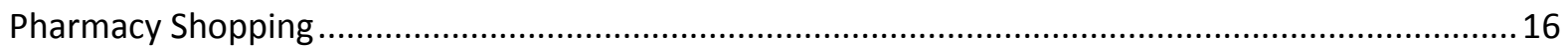

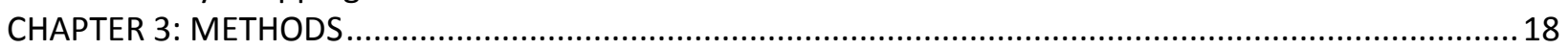

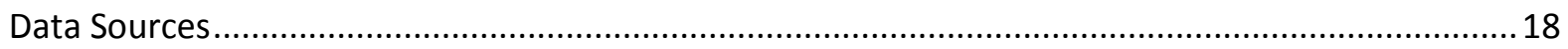

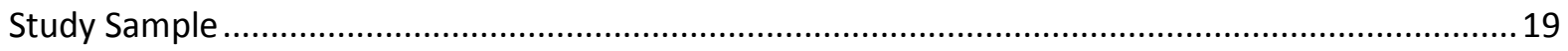

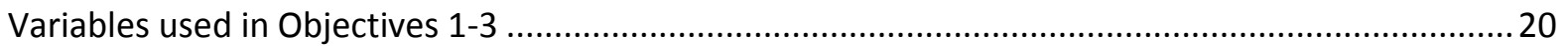

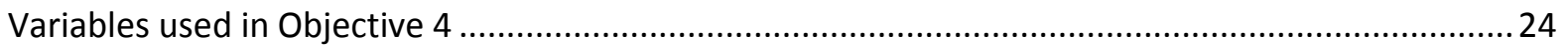

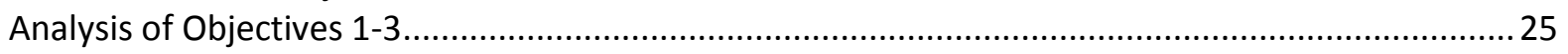

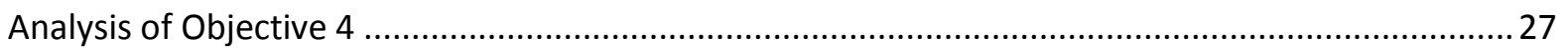

CHAPTER 4: RESULTS

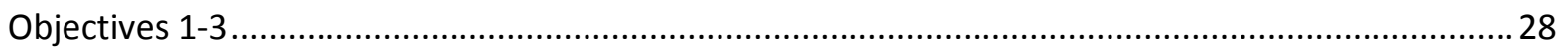

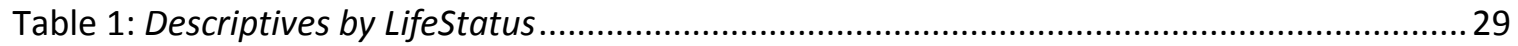

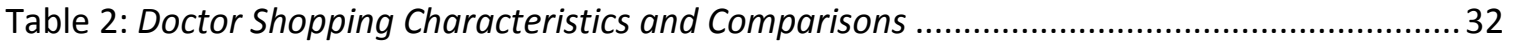

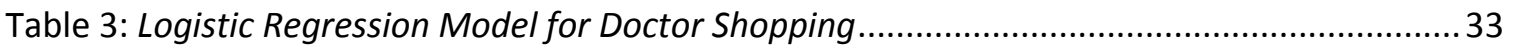

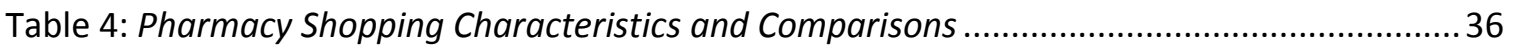

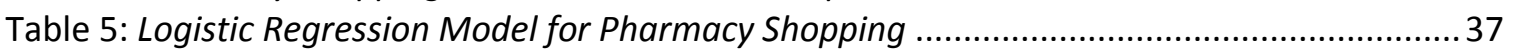

Table 6: Logistic Regression Model for Controlled Drug Substance Mortality............................... 38

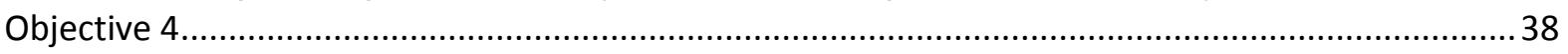

Table 7: Characteristics of Decedents with at Least One Controlled Drug Substance Detected

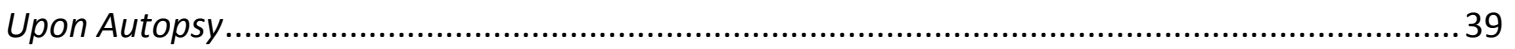

Table 8: Characteristics and Comparisons of Decedents by Controlled Drug Substance

Prescription Verification.......................................................................................................... 40

Table 9: Characteristics and Comparisons of Decedents with at Least One Controlled Drug

Substance Not Verified by a Prescription ..................................................................................... 41

Table 10: Logistic Regression Model for Controlled Drug Substance Prescription Verification ..... 42

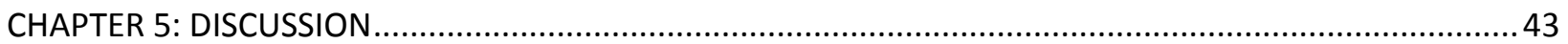

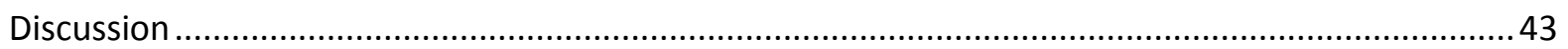

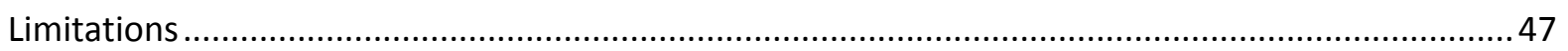

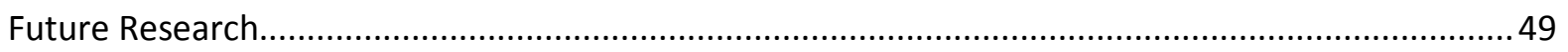

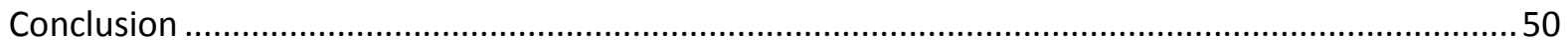

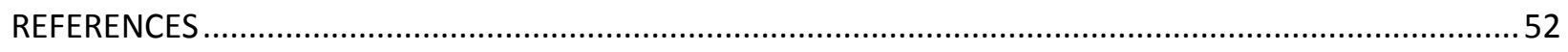

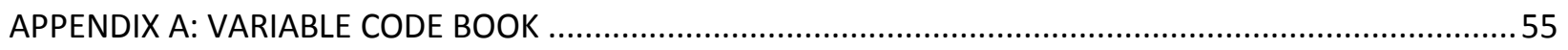




\section{Chapter 1}

\section{Introduction}

\section{Background}

Prescription drug abuse continues to be a problem in the United States. ${ }^{1-12}$ West Virginia has a higher than average prescription drug abuse rate than the national average.,12 Even though noncontrolled drug substances such as antidepressants are abused, the most commonly abused drugs are controlled drug substances. ${ }^{1,4,8,11,13}$

Federal and state governments and professional associations have tried to prevent and reduce prescription drug abuse through regulations and policies. ${ }^{14,15}$ To help reduce prescription drug abuse, West Virginia implemented a controlled substance monitoring program in $1995 .{ }^{15}$ Even with this program, prescription drug abuse rates in the state have continued to increase. ${ }^{7,12}$ Although a controlled substance monitoring program can be a useful tool, evidence shows that only a fraction of healthcare professionals use them. ${ }^{16}$

There are many different avenues to divert prescription drugs. ${ }^{17-23}$ Pharmacy shopping and doctor shopping are avenues to prescription drug diversion which healthcare professionals can help to reduce in daily practice, especially with the aid of controlled substance monitoring programs. Several studies have investigated doctor shopping..$^{7,13,24-27}$ One study in West Virginia examined patterns of prescription drug abuse among those who died with a prescription drug detected upon autopsy and found that approximately $21 \%$ of deaths were related to doctor shopping. ${ }^{7}$ There has been very little research in the area of pharmacy shopping. ${ }^{26,28,29}$ Although, one study did find that the greater the number of providers used, the number of pharmacies also increased based on data from the Massachusetts Prescription Monitoring Program. ${ }^{29}$ 
There has been much discussion for several decades about balancing the benefits of using controlled drug substances and the risk of prescription drug abuse. ${ }^{14,15,17}$ Some argue that pain management is undertreated in the United States, especially in those patients who have a substance addiction, ${ }^{15}$ and should be treated with opioids and other controlled drug substances. ${ }^{23}$ Others argue that there are too many regulations and potential repercussions such as litigation and criminal charges that prevent proper prescribing of controlled drug substances to treat pain or other diseases. ${ }^{22}$

To the authors' knowledge there has been no study to date that compared the use of controlled drug substances in living patients to use in persons who died with controlled drugs detected upon autopsy. The verification of prescriptions for drugs detected upon autopsy in decedents has been studied in West Virginia using data that spanned a single year. ${ }^{7}$ Studies verifying prescriptions for controlled drug substance use in decedents covering a longer time period are lacking.

\section{Purpose of the Study}

The study specifically examined the use of controlled drug substances in West Virginia, due to the state's high rate of prescription drug abuse. ${ }^{7,12}$ Data from the West Virginia Board of Pharmacy's Controlled Substance Monitoring Program and the Office of the Chief Medical Examiner's Forensic Drug Database were used to determine the prevalence of doctor shopping and pharmacy shopping related to controlled drug substance use in West Virginia. The study provided evidence of doctor shopping and pharmacy shopping in West Virginia by comparing controlled drug substance records of living versus deceased subjects. The study also added to the literature by verifying presence of prescription records for controlled drug substances detected upon autopsy in decedents over multiple years, as opposed to a single year. ${ }^{7}$

The purpose of the study was to answer the overall question of what patterns are present related to controlled drug substance use in West Virginia, specifically pharmacy and doctor shopping. 
Chapter 1: Introduction

The specific research questions that the study addressed include:

Research Question 1: What factors are significantly related to doctor shopping?

Research Question 2: What factors are significantly related to pharmacy shopping?

Research Question 3: What factors are significantly related to the odds of dying with controlled drug substance use?

Research Question 4: What factors are significantly related to controlled drug substance prescription verification?

\section{Significance of the Study}

There have been few studies examining doctor shopping, and none comparing doctor shopping in living subjects who are using controlled drug substances with subjects who have died with a controlled substance detected upon autopsy. Very little has been studied with regard to pharmacy shopping in persons who died. The study will compare pharmacy and doctor shopping between living and deceased subjects. The findings generated from this research will raise awareness of issues associated with prescribing and dispensing controlled drug substances, and consider need for interventions to modify doctor and pharmacy shopping behaviors for controlled drug substances.

\section{Study Objectives}

The study objectives were to compare living and deceased subjects for doctor shopping and pharmacy shopping. Another objective was to identify factors that significantly predict the odds of dying from controlled drug substance use. Finally, the last objective was to identify significant factors related to having prescriptions for controlled drug substances among decedents who had a controlled drug substance detected on autopsy. 


\section{Objective I: Doctor Shopping}

Objective 1: To identify significant factors associated with doctor shopping.

Null Hypothesis 1a: There is no significant difference between the proportion of subjects who doctor shop and those who do not based on life status.

Null Hypothesis $1 b$ : There is no significant difference between the proportion of subjects who doctor shop who are living versus deceased by age group, pharmacy shopping, number of different controlled drug substances dispensed and number of prescriptions dispensed.

Null Hypothesis 1c: There are no significant factors associated with doctor shopping.

\section{Objective II: Pharmacy Shopping}

Objective 2: To identify significant factors associated with pharmacy shopping.

Null Hypothesis 2a: There is no significant difference between the proportion of subjects who pharmacy shop and those who do not based on life status.

Null Hypothesis 2b: There is no significant difference between the proportion of subjects who pharmacy shop who are living versus deceased by age group, doctor shopping, number of different controlled drug substances dispensed and number of prescriptions dispensed.

Null Hypothesis 2c: There are no significant factors associated with pharmacy shopping.

\section{Objective III: Controlled Drug Substance Mortality Odds}

Objective 3: To identify significant factors associated with the odds of dying from use of controlled drug substances.

Null Hypothesis 3: There are no significant factors associated with the odds of dying related to the use of controlled drug substances. 


\section{Objective IV: Controlled Drug Substance Prescription Verification}

Objective 4: To identify significant factors associated with controlled drug substance prescription verification (i.e., having verified prescriptions for the controlled drug substances detected upon autopsy).

Null Hypothesis 4a: There is no significant difference between the proportion of decedents between the verified group and the non-verified group based on age group, number of different controlled drug substances (autopsy), and gender.

Null Hypothesis 4b: There are no significant factors associated with controlled drug substance prescription verification.

\section{Study Assumptions}

The primary assumption of the study is that living and deceased groups have similar drug use patterns. It is unknown if the subjects are getting controlled drug substances from another source even though they have at least one verified prescription for a controlled drug substance identified by the Controlled Substance Monitoring Program. It is also assumed that living and deceased groups have similar use of other prescription medications (e.g., over-the-counter medications and illicit drug use) because only controlled drug substance use is captured in the Controlled Substance Monitoring Program, the only source used in the study for objectives 1-3. 


\section{Chapter 2}

\section{Background}

\section{Prescription Drug Abuse}

Studies have examined prescription drug abuse through the use of databases ${ }^{1,3-5,7,13}$ and by surveys of patients ${ }^{2,6}$ and community pharmacists. ${ }^{30}$ An Australian study of heroin decedents aged 1524 found that poly-drug use was detected in $90 \%$ of the cases and of these $80 \%$ involved prescription drugs, predominately benzodiazepines and opioids. ${ }^{13}$ A study by McCabe and colleagues showed that the past year prevalence of prescription sedative abuse, sedative dependence, opioid abuse, and opioid dependence increased from 1991-1992 to 2001-2002. ${ }^{1}$ Through the National Household Survey from 1991-1993, it was found that nearly 1.3 million Americans experienced a problem with prescription drug use that signified a psychological dependence with heavy daily use. ${ }^{3}$ Maxwell compiled several reports from multiple data sources into one document on the growing abuse of prescription drugs. ${ }^{11}$ According to the 2002 National Survey on Drug Use and Health (NSDUH) approximately 29.6 million Americans used pain relievers non-medically in their lifetime. By 2005 the number increased to 32.7 million Americans, of whom 18-25 year olds used more pain relievers, benzodiazepines, and muscle relaxants than any other age group. ${ }^{11}$ The Drug Abuse Warning Network Medical Examiner Reports (DAWN ME), in which only 6 states participated, showed that in 2003, 66-93\% of drug-related deaths involved more than one drug. ${ }^{11}$ The National Center for Health Statistics reported that opioid analgesic deaths increased by $91 \%$ from 1991 to $2002{ }^{11}$ The National Forensic Laboratory Information System reported that from 2001-2005 narcotics and benzodiazepines represented nearly 5\% of all drugs analyzed. ${ }^{11}$ Paulozzi and colleagues found that unintentional drug death rates increased an average of $5.3 \%$ from 1979-1990 and 18.1\% from 1990-2002. ${ }^{4}$ They found that opioid analgesics increased at a rate of $91.2 \%$ from $1999-2002$, while heroin and cocaine increased by $12.4 \%$ and $22.8 \%$, respectively. ${ }^{4}$ From the 
National Center on Addiction and Substance Abuse (CASA) 2005 report there was a 14\% increase in the US population and a $94 \%$ increase in the abuse of controlled prescription drugs from $1992-2003 .{ }^{9}$ CASA 2005 reported that 15.1 million people admitted to abuse of prescription drugs. ${ }^{9}$ The Substance Abuse and Mental Health Services Administration (SAMHSA) survey showed the highest increase in abuse was with oxycodone. ${ }^{8}$ These research studies and reports provide evidence of a prescription abuse problem, particularly poly-drug use and opioid abuse, in the United States.

According to the Office of National Drug Control Policy (ONDCP) and the National Survey on Drug Use and Health, prescription drug abuse is one of the most serious public health threats in West Virginia. ${ }^{12}$ An average of $5 \%$ of those aged 12 or older in West Virginia used pain relievers for nonmedical purposes in 2005-2006. ${ }^{12}$ A 2006 study of overdose deaths in West Virginia found the deaths to be primarily associated with non-medical use and diversion of pharmaceuticals, mostly opioid analgesics. $^{7}$ Opioid analgesics were taken by $93.2 \%$ of decedents with only $44.4 \%$ of them having been prescribed these drugs. ${ }^{7}$

Risk factors have been identified for prescription drug abuse. ${ }^{2,3}$ A study of college students who used prescriptions for non-medical purposes and illicit drugs found marijuana use correlated heavily with non-medical use of prescription drugs, while being black and attending a commuter college were negatively correlated with non-medical use of prescription drugs. ${ }^{2}$ The 1991-1993 National Health Survey found that those at greater risk for a problem with prescription drugs were older adults, females, those with poor/fair health, and daily alcohol drinkers. ${ }^{3}$ The 2002-2005 National Survey on Drug Use and Health found that $4.8 \%$ of people 12 years and older had taken a prescription pain reliever nonmedically, of which males (especially those between 18 and 34 years) tended to have higher rates of abuse. $^{10}$ Those aged $18-25$ years had the highest rate for both genders. ${ }^{10}$ A report from the DAWN ME similarly found higher rates of opiate deaths in those aged 21-54 years by age and also in males. ${ }^{11}$ Of those who abused prescription pain relievers for non-medical purposes, $57.7 \%$ used hydrocodone and 
21.7\% used oxycodone. ${ }^{10}$ A study that surveyed patients with the Abuse Index found patients with chronic non-cancer pain were more likely to misuse drugs. ${ }^{6}$ Chabal and colleagues found that $34 \%$ of pain clinic patients met at least one of the criteria for abuse, and suggest a five point prescription opiate abuse checklist that could be used in normal clinical interactions. ${ }^{31}$ Turk et al. found that pain behaviors (i.e., behavioral manifestations of pain, distress, and suffering, as well as functional disability and distress) were significant predictors of being prescribed opiates compared to patients who were not. ${ }^{32}$ Thus patients with these factors may be at greater risk for prescription drug abuse so healthcare professionals should carefully monitor such patients when prescribing/dispensing controlled drug substances. Identifying risk factors and behaviors is only one way healthcare professionals can prevent prescription drug abuse. Discovering how and why patients divert or misuse prescription drugs would add more insight on how to prevent prescription drug abuse.

\section{Implications of Prescription Drug Abuse}

Although the US makes up for only $4.6 \%$ of the world's population, they consume $80 \%$ of the global opioid supply and $99 \%$ of the global hydrocodone supply. ${ }^{33}$ Paulozzi and colleagues found that the increase in opioid deaths followed the increase of sales for each type of opioid. ${ }^{4}$ Based on the DEA Automation of Reports and Consolidated Orders System (ARCOS) report of prescription drug sales, sales of oxycodone surpassed hydrocodone since $2000 .{ }^{11}$ Compton and Volkow highlighted a finding by Zacny and colleagues (2003) that increases in problems were associated with increases in prescriptions particularly for oxycodone, fentanyl, and morphine prescriptions. ${ }^{34}$ Hydrocodone/APAP was reported as the number one prescribed drug from the $R X$ List. $^{17}$ According to Kuehn, the 2005 International Narcotics Control Board reported a $60 \%$ increase in domestic use of hydrocodone in the US between

2002 and $2004 .{ }^{17}$ As prescriptions numbers increase there is a logical increase in the risk of abuse of prescription drugs. 
The 1995 CASA report estimated $\$ 77.6$ billion of healthcare and disability costs are related to substance abuse. ${ }^{35}$ The 2004 DAWN ED report, as described by Maxwell, found that there were 1.3 million emergency department visits associated with drug misuse and abuse, with most involving multiple drugs. ${ }^{11}$ Of those visits involving a single drug, 33\% were opiates, $23 \%$ were benzodiazepines, and $16 \%$ were muscle relaxants. ${ }^{11}$ Those aged $21-54$ years had the highest rates of emergency department visits. ${ }^{11}$ The Treatment Episode Dataset report, as given by Maxwell, found that between 1944 and 2004 opiates other than heroin increased from 14,197 to 60,017 with regard to the number of patients admitted to treatment centers; these patients tended less likely to be male and a person of color. ${ }^{11}$ Approximately $10 \%$ of US patients in treatment indicated their principle drug of abuse is a prescription drug. ${ }^{36}$ Rice and colleagues estimated the total losses to the economy in 1988 related to alcohol abuse, drug abuse, and mental illness were approximately $\$ 273.3$ billion; $\$ 58.3$ billion was attributed to drug abuse alone, which most likely underestimates the true cost to society. ${ }^{37}$ McLellan et al. reported that many expensive and disturbing social problems are associated with drug dependence. ${ }^{38}$ There were 4,100 arrests for drug abuse in West Virginia in 2006, along with 1,249 treatment admissions for abuse of opiates other than heroin. ${ }^{12}$ These reports show the burden of increased utilization of controlled substances, particularly opiates, on healthcare, societal and economic costs.

Prescription drug abuse does not just affect those abused and society; it has real implications for physicians as well. Physicians face the dilemma of prescription drug abuse when treating illnesses that may require controlled drug substances including pain management. ${ }^{14,15,17}$ Managing pain was emphasized as the $5^{\text {th }}$ vital sign. ${ }^{39}$ Opioids have an important role in the treatment of pain; ${ }^{15}$ however, there is also evidence that opioids may not always be the best treatment. ${ }^{22}$ Pain should be treated along with the use of clinical risk management tools to decrease abuse and diversion. ${ }^{40}$

Opioid abuse has made pain management even more complicated since there tends to be an under-treatment of pain, especially in patients who abuse prescription drugs. ${ }^{15}$ Many states have 
regulations that prohibit physicians from prescribing controlled substances to individuals addicted to controlled substances. ${ }^{41}$ Drug dependence has often been treated as an acute illness; however, it causes changes in brain chemistry and function that lead to long-term effects. ${ }^{38}$ It is important that it be treated and monitored as a chronic illness. ${ }^{38}$ Patients with pain should be treated for pain, although heightened patient monitoring should be employed with termination of medication if they deviate from the plan. ${ }^{23}$ However, heightened scrutiny on physicians' prescribing may have an adverse effect on patient care. ${ }^{23}$ Regulations should not impede the treatment of pain in addicts, but rather should strictly manage treatment to prevent controlled drug substances from being abused.

\section{Prescription Drug Regulations}

Researchers and experts agree that appropriate pain management and prevention of prescription drug diversion /abuse is a delicate balance. ${ }^{14,15,17}$ It is often complicated by such things as regulations and litigations which put pressure on physicians. Doctors may face litigation for failure to treat or for under-treatment of pain, ${ }^{22,40}$ or criminal charges for patient abuse, addiction or death. ${ }^{22}$ Patients contribute to the problem since in one study, 28 out of 90 patients provided physicians with an inaccurate history of controlled substance use. ${ }^{22}$ Of those that reported opioid use, 16 out of the 90 were under-reporters and 8 out of 42 patients taking a benzodiazepine under-reported the use of benzodiazepines. ${ }^{22}$ Laws and regulations, triplicate prescriptions and prescription monitoring programs have been used to offset the delicate balance in favor of appropriate use of prescription drugs for patient management over prescription drug diversion/abuse.

From the early $19^{\text {th }}$ century, physicians and regulators have been concerned over the abuse potential of certain drugs such as narcotics. ${ }^{14,15}$ They created laws to help regulate the manufacturing and distribution of these drugs. ${ }^{14,15}$ The Pure Food and Drugs Act of 1906 created the "dangerous" drugs list which included habit forming substances. ${ }^{14}$ The Harrison Act of 1914 created a register of narcotic distributers and in 1919 made it a legitimate professional practice.$^{14}$ The Porter Act of 1929 established 
Narcotic Hospitals. ${ }^{14}$ The Narcotics Manufacturing Act of 1960 created a closed system of narcotics manufacturing and distribution, licensed manufacturers, and established quotas for natural and synthetic opiates. ${ }^{14}$ The Food Drug and Cosmetic Act of 1938 - 1951 created legend drugs, although narcotics were still under the control of the Department's Federal Bureau of Narcotics (FBN). ${ }^{14}$ Narcotic regulation was important in the United States and worldwide. ${ }^{14}$ The 1961 Single Convention established international control and a global standard and is still the lynchpin of narcotic regulatory arrangements of present day. ${ }^{14}$ The Controlled Substance Act combined the Federal Bureau of Narcotics and the FDA Bureau of Drug Abuse Control to form the Bureau of Narcotics and Dangerous Drugs, which controls interstate commerce. ${ }^{14,40,42}$ The Drug Abuse Prevention and Control Act of 1970 consolidated more than 50 federal drug laws. ${ }^{42}$ The 1971 Psychotropic Convention was similar to the 1961 Single Convention, which was under the same assumption that supply control provided the key to eliminating substance abuse. ${ }^{14}$ In 1973 the Bureau of Narcotics and Dangerous Drugs created the Drug Enforcement Agency. ${ }^{14}$ This is just a brief history of federal regulations to control prescription drug abuse through supply channels such as manufacturing and distribution of narcotics.

Other laws and regulations have been directed specifically at healthcare providers, such as educational requirements and surveillance tools. To best manage patients while minimizing drug misuse or abuse, it is important that principles of pain management be incorporated into medical schools as well as continuing education. ${ }^{17}$ West Virginia mandated a curriculum in pain management and palliative care in its medical schools. ${ }^{40}$ The federal government included regulations for establishing prescription monitoring programs to further provide information about possible drug abuse to law enforcement and physicians. ${ }^{15}$

\section{Prescription Monitoring Programs}

Prescription monitoring programs (PMPs) have increased in number over the years. There were 10 in 1992 and 15 in 2002, which covered 47\% of the population and 45\% of the nation's pharmacies. ${ }^{43}$ 
There are currently 27 PMPs, ${ }^{44}$ covering 23 states in the country. ${ }^{45}$ The major problems associated with PMPs are passing legislation to establish a PMP, creating the PMP and securing funding for the program. ${ }^{44}$

Even though PMPs were developed to identify patterns of prescription drug abuse through dispensing and have been a useful tool to reduce diversion, ${ }^{15}$ they are inadequate alone to reduce prescription drug abuse. A survey of prescription monitoring program directors was conducted to examine data captured by the programs, data sharing procedures, healthcare training, program goals and evaluation efforts. ${ }^{45}$ Although most states collect Schedule II prescription data, there are states that collect Schedules II-V while other states vary somewhere in between. ${ }^{15,45}$ Most pharmacies report data to PMPs that varies from one hour to no more than a week after the prescription has been filled. ${ }^{45}$

The majority of PMPs were created with the goal to provide patients with better access to opioids for pain management and to increase physician comfort in prescribing opioids, while reducing abuse. ${ }^{45}$ Yet very few states use the data for epidemiological studies, to conduct evaluations of the PMP, or to provide user guidelines. ${ }^{45}$ Only eight states reported developing educational programs based on data collected through the PMP. ${ }^{45}$ Few states provide suspicious use information to physicians proactively, while other states do not allow healthcare professionals to access information at all. Some states only allow physicians to access data contained in the PMP, and some states only allow information to be obtained upon request. ${ }^{15,45}$ Weissman and Johnson discussed four negative effects of PMPs: 1) placing restrictions on physician practice; 2) affecting patient access to opioids; 3 ) stigmatizing patients; and 4) negatively impacting physician perceptions of regulations, resulting in modified medical practices. ${ }^{46}$ There is also a lack of communication between states which may cause a decrease in controlled substance use in one state but cause an increase in use in contiguous states without PMPs. ${ }^{42}$ Collectively, these facts support the need for a national program. ${ }^{15}$ PMP administrators are currently working on a central database for interstate access to PMPs. ${ }^{45}$ 
The West Virginia Schedule II program started in 1995 by the State Board of Pharmacy. ${ }^{15}$ Now the prescription monitoring program in West Virginia includes Schedule II through Schedule IV drugs. ${ }^{47}$ Law enforcement agencies find the program useful for obtaining information to deter or prosecute doctor shoppers. ${ }^{15}$

Through a survey of physicians' attitudes toward using a prescription monitoring system in southwest Virginia, it has been shown that the majority found the prescription monitoring program to be useful. ${ }^{16}$ However, only about $11 \%$ actually used the prescription monitoring program data. ${ }^{16}$ The majority of physicians felt their prescribing was being monitored through the prescription monitoring program; furthermore, $23 \%$ felt their ability to manage pain for their patients was negatively impacted. A study of physician attitudes in West Virginia found that $81 \%$ of physicians reported using the Controlled Substance Monitoring Program, but only 22\% reported doctor shoppers that they encountered. ${ }^{48}$ However, $85 \%$ responded that they would report doctor shoppers if there was a law that protected them. ${ }^{48}$ PMPs with the right resources have the potential to be useful tools for healthcare professionals.

Even though prescription monitoring programs theoretically provide a useful tool to help deter diversion and abuse of prescription drugs, it is important to realize that more research is needed on their effectiveness. A study by Katz et al. used the PMP in Massachusetts to examine the use of Schedule II opioid prescriptions and concluded that the PMP could be a useful surveillance tool. ${ }^{29} \mathrm{~A}$ study by Wilsey et al. used the California PMP to examine the utilization of multiple providers for controlled drug substances. ${ }^{49}$ They found that as the number of different controlled drug substances increased, the number of providers used increased as well. ${ }^{49}$ A study in France using a program from the general health insurance system found that after making healthcare professionals aware of their patients who consumed excessive doses, there was a decrease in consumption and a decrease in doctor shopping. ${ }^{50}$ More education on utilization and awareness of prescription monitoring programs is 
needed so that healthcare professionals can use prescription monitoring programs to their fullest potential. ${ }^{16}$

Patients who demand certain prescriptions put physicians in a difficult position. ${ }^{44}$ PMP data can be a useful tool when physicians do not have medical records for new patients. ${ }^{44}$ PMPs assist physicians in prescribing controlled drug substances to those with legitimate treatment needs by identifying potential abusers. ${ }^{44}$

Simoni-Wastila and Tomkinsa conclude in their study that multiple copy prescriptions and electronic data transfer systems alone are not effective tools for diverting pharmaceuticals. ${ }^{51}$ They lack the necessary tools to assess and process data on prescribing and dispensing patterns. ${ }^{51}$ Thus, an effective program is needed that identifies and reduces inappropriate prescribing and dispensing while still allowing legitimate prescribing and dispensing to occur. ${ }^{51}$

\section{Means of Obtaining Prescription Drugs - Diversion}

There are several different channels available for people to divert prescription drugs. A study in Miami, Florida found that sources of drug abuse were very diverse and included physicians, pharmacists, a patient's relatives, doctor shopping, and hospital and pharmacy theft. ${ }^{18}$ The researchers concluded that while doctor shopping and internet sources receive much attention with regard to diversion, there are other factors that deserve attention, including patients, Medicaid recipients and pharmacies. ${ }^{18} \mathrm{~A}$ Canadian abuse study by Fischer et al. found that most diverted drugs came from the medical system or through friends or partners. ${ }^{20}$ A presentation by Moric, as reported by Kuehn, also emphasized that abusers were not getting prescriptions from physicians, but from friends, family and the internet. ${ }^{17}$ In 2003, two million doses were reported stolen from the supply chain, mostly from pharmacies. ${ }^{21}$ A study by Manchikanti et al. found that $42 \%$ of patients who were prescribed opioids failed to show opioid concentrations in their urine, ${ }^{22}$ which implied that they were selling, giving away, or not using their prescribed medications. According to Hurwitz, studying the pattern of diversion is important to resolve 
unanswered questions including: whether source of drug is from prescriptions; the role of theft or fraud; limitations of ability to detect diversion; legitimacy of doctor and patient; and whether patient is giving/selling his/her prescription. ${ }^{23}$

Not only are the sources of drugs important, but so are the reasons why patients abuse prescription drugs. A study done in the UK found reasons why patients abused prescription drugs included selling part of the prescriptions to afford a preferred drug, buying a private prescription, and supplementing current treatment due to dissatisfaction. ${ }^{52}$ Anesthesiologists and pain management physicians were asked to rank a list of 13 aberrant drug taking behaviors. ${ }^{53}$ Although there was a great deal of difference among the rankings, there was a common trend to rank illegal behaviors the highest, followed by alteration of dosage route, and escalation of dosage..$^{53}$ It is important for healthcare professionals to have proper education in addiction medicine to deter aberrant drug taking behaviors. ${ }^{53}$ In order to deter diversion prescribers, drug treatment services, pharmacies, and law enforcement agencies need to work together. ${ }^{52}$

\section{Doctor Shopping}

Preventing doctor shopping has been a primary focus in reducing prescription drug abuse.

Several studies have examined doctor shopping. ${ }^{7,13,24-27}$ Two studies examined doctor shopping by using decedent data. ${ }^{7,13}$ Researchers found that among all decedents in West Virginia who died of unintentional pharmaceutical overdoses in 2006 involved diversion (63\%) and doctor shopping (21.4\%). ${ }^{7}$ Although diversion was greatest in those aged 18-24 years, doctor shopping was more prevalent in a slightly older age group (35-44 years and predominantly women). ${ }^{7}$ Australian decedent records were examined and showed that there were drug-seeking behaviors identified in the year prior to death. ${ }^{13}$ These behaviors included doctor-visitation rates, number of different doctors seen, and the rates of prescriptions peaking the year before death. ${ }^{13}$ A study by Katz et al. used a prescription monitoring 
program for controlled drug substances to examine trends. ${ }^{29}$ They found that the greater the number of prescribers used, there was a greater number of pharmacies used which led to questionable activity. ${ }^{29}$

A study in France surveyed physicians and examined claims data for buprenorphine maintenance therapy. ${ }^{27}$ The investigators found that doctor shopping may not be a deviant behavior, but may actually be influenced to some extent by physicians. ${ }^{27}$ The study reported that patients may doctor shop because they are dissatisfied with inappropriate care and their relationship with their physician. ${ }^{27}$ The investigators concluded that physicians' attitudes toward treating opiate-dependent patients can influence doctor shopping behaviors. ${ }^{27}$

Identifying patterns of escalating use, such as an increase in doctor visits, increases in number of different doctors seen, or an increase in rate of prescriptions may be an opportunity for interventions by healthcare professionals to perhaps reduce mortality. ${ }^{13}$ A study in France on high dosage buprenorphine use found that doctor-shopping could be reduced by adequate indicators on prescription databases. ${ }^{25}$ In this way, the effect on legitimate use of buprenorphine would be minimized. ${ }^{25} \mathrm{~A}$ database study of elderly Medicare patients in Quebec found that a single primary care physician lowered the risk of potentially inappropriate drug combinations across all drug groups. ${ }^{26}$ The study concluded that a single primary care physician and a single dispensing pharmacy may prevent potentially inappropriate drug combinations. ${ }^{26}$

\section{Pharmacy Shopping}

Pharmacy shopping has not been studied very much in the literature. ${ }^{26,28,29}$ A study by Buurma defined pharmacy shopping as visiting two or more pharmacies. ${ }^{28}$ They examined pharmacy shopping through a Dutch insurance company and found only a small percentage of pharmacy shoppers (10.8\%), of which $98.8 \%$ were considered light shoppers. ${ }^{28}$ Although pharmacy shopping appeared to not be a major concern in the Netherlands, it may be more of a problem in the United States. A study by Katz et 
al. found a direct correlation between number of prescribers visited and number of pharmacies used, which often led to questionable activity with Schedule II controlled drug substances. ${ }^{29}$

A study showed that having a single primary care physician and using a single pharmacy reduce the odds of a potentially inappropriate drug combination. ${ }^{26}$ Even though a potentially inappropriate drug combination is not related to misusing drugs, it could be extrapolated that having a single pharmacist would increase the probability of identifying aberrant behaviors of drug misuse. Past literature, research and regulations have primarily focused on physician prescribing and doctor shopping; perhaps the community pharmacist can play a more significant role in prescription drug abuse. 


\title{
Chapter 3
}

\author{
Methods
}

\section{Data Sources}

\section{Controlled Substance Monitoring Program}

The Controlled Substance Monitoring Program (CSMP) is a database that includes all dispensing records for Schedule II through Schedule IVcontrolled drug substances (CDS) in the state of West Virginia. It includes the drug name, drug strength, drug quantity, date filled, the NDC, the DEA number of the doctor, the DEA number of the pharmacy, the pharmacy zip code, and the patient's name, date of birth, and zip code.

\section{Forensic Drug Database}

The Forensic Drug Database (FDD) was created as part of the Forensic Drug Information (FDI) project for use by medical examiners and forensic professionals. The Office of the Chief Medical Examiner of the State of West Virginia and the West Virginia Center for Drug and Health Information, which is a service of the West Virginia University School of Pharmacy, are partners in the FDI project. The FDI project was partly funded by a grant from the National Institute of Justice. The FDD is a computerized database that allows data about drug-induced or drug-related deaths to be collected and compiled remotely from anywhere in the world through the Forensic Drug Information website. From the website, participating medical examiners enter data directly into an internet secured password protected case entry form. The case entry form has drop down boxes to ease data entry, as well as areas to write in additional information. The case entry forms are converted into several database worksheets. The FDD contains case-specific information including decedent characteristics, drugs detected upon autopsy, pre-existing conditions, cause of death, toxicology and other factors relating to 
drug-induced or drug-related deaths. The main goal of the FDD is to identify patterns and characteristics related to drug toxicity.

\section{Study Sample}

The sample population consisted of subjects who were 18 years or older and who used Schedule II through Schedule IV controlled drug substances (CDS) in the state of West Virginia from July 1, 2005December 31, 2007. The study samples will be described below by objectives.

\section{Study Sample for Objectives 1-3}

The CSMP was the main data source used for objectives 1-3. The FDD dataset was used only to identify the two comparator groups (living vs. deceased) for objectives 1-3. The FDD was not used as a primary data source because other drug use information could not be determined for the living group, such as other drugs used. Subjects who had at least one CDS prescription (Schedule II through Schedule IV) in the CSMP and were not present in the FDD were assumed to be living subjects. Therefore, the living group was comprised of these subjects. The deceased group consisted of subjects found in the CSMP that were also identified in the FDD. Subjects were excluded from the study sample for objectives 1-3 if they were younger than 18 years of age. FDD subjects were not included in the sample population if they were not found in the CSMP for the dates of the study period.

\section{Study Sample for Objective 4}

The FDD was the main data source for objective 4. All subjects who had at least one CDS detected upon autopsy during the study period were included. The Office of the Chief Medical Examiner of the State of West Virginia determines from the CSMP data if there was a verified prescription for the CDS detected upon autopsy over a 60 day window prior to death. This information was used to identify two comparator groups (verified vs. non-verified) for objective 4.

The verified group consisted of subjects who had a verified prescription in the CSMP for all CDS (Schedule II through Schedule IV) that were detected upon autopsy. These subjects may or may not 
have died of other drug substances (other prescription drugs (non-controlled drug substances), overthe-counter medications, and/or illicit drugs) which were not examined in the study. The non-verified group consisted of decedents with at least one CDS detected upon autopsy without a verified prescription. Each subject in the non-verified group did not have a prescription in the CSMP for at least one CDS detected upon autopsy. Subjects in the non-verified group may have some, but not all, prescriptions for the CDS that were detected upon autopsy. These subjects may or may not have died of other drug substances (other prescription drugs (non-controlled drug substances), over-the-counter medications, and/or illicit drugs) which were not examined in the study.

Subjects were excluded if they were younger than 18 years of age. Subjects who only had other prescription drugs (non-controlled drug substances), over-the-counter medications, and/or illicit drugs detected upon autopsy were excluded because they did not have a CDS detected upon autopsy.

\section{Variables used in Objectives 1-3}

\section{Identifying Variables}

First and last name and date of birth were used to merge the cases found in the FDD to the CSMP, but were not used in analyses. First and last name were converted to a unique identifier, and date of birth was converted to the variable age by the technicians of the CSMP before the researchers received the data. The doctor's DEA number was the only variable in the CSMP to identify the doctor. The doctor's DEA number was only used to report the number of doctors that a subject visited and was not used to identify the practitioner. The pharmacy DEA number was used to identify the number of pharmacies a subject used. The pharmacy DEA number was not used to identify pharmacies in the study. No unique identifier was used to identify single entities in the results. All results were reported in aggregate. 


\section{Life Status}

Life status was created as a dichotomous variable to identify the living and deceased groups. (See Study Sample for Objectives 1-3 for a description of these two groups.) Age

Age is a continuous variable. Date of birth and the last fill date from the CSMP were used to calculate age before the researchers received the data. Age was used to create the categorical variable age group. Age was included as a continuous variable in each of the logistic regression equations. Age Group

Age group was created as a categorical variable, which consists of six groups: 18-24, 25-34, $35-$ $44,45-54,55-64$, and $\geq 65$. Age group was used as a variable in the bivariate analysis for each of the objectives.

\section{Number of Doctors}

Number of doctors was defined as the number of doctors who prescribed dispensed CDS prescriptions per subject for the six months prior to the last CDS prescription dispensed. It was created with the variables date filled, doctor DEA and unique ID which can all be found from the CSMP. Number of doctors was used to define doctor shopping.

\section{Doctor Shopping}

The variable doctor shopping was based on an article by Hall et al. which defined it as those who had prescriptions from at least five clinicians in the year preceding death. ${ }^{7}$ A study by Katz et al. defined doctor shopping as using four or more prescribers. ${ }^{29}$ Due to the time span of data available in the present study, the definition of doctor shopping was operationalized to consider a time period of six months prior to the last prescription filled. Therefore, doctor shopping was defined with less doctors per time period then the Hall et al. study. In the present study, doctor shopping is a 
dichotomous variable in which subjects who were dispensed prescriptions from four or more clinicians over a six month period from the last date filled were considered doctor shoppers; those who visited less than four clinicians were considered non-doctor shoppers. Four was chosen as a conservative measure to reduce the propensity of misclassifying an individual as a shopper. The variable number of doctors was used to define doctor shopping.

\section{Number of Pharmacies}

Number of pharmacies was defined as the number of pharmacies that dispensed CDS prescriptions per subject for the six months prior to the last CDS prescription dispensed. It was created with the variables date filled, pharmacy DEA, and unique ID which can all be found from the CSMP. Number of pharmacies was used to define pharmacy shopping.

\section{Pharmacy Shopping}

The variable pharmacy shopping was based on an article by Buurma $\mathrm{H}$, et al. which defined pharmacy shoppers as those subjects who went to two or more pharmacies over a time period of a

year. ${ }^{28}$ The authors reported that $98 \%$ of shoppers were considered light (only using two pharmacies). ${ }^{28}$ A study by Katz et al. defined pharmacy shopping as using four or more pharmacies. ${ }^{29}$ In the present study, pharmacy shopping was defined as a dichotomous variable with those subjects who were dispensed CDS prescriptions from four or more pharmacies over a six month period from the last date filled as pharmacy shoppers, and those who had less than four pharmacies dispense CDS prescriptions as non-pharmacy shoppers. Four was chosen as a conservative measure to reduce the propensity of misclassifying individual as a shopper. The variable number of pharmacies was used to define pharmacy shopping.

\section{Date Filled}

Date filled was a variable included in the CSMP. It contains the date when the pharmacy dispensed the CDS prescription. It was used to determine the number of prescriptions dispensed, the 
number of doctors, the number of pharmacies, and the number of different CDS dispensed. Date filled itself was not used in analysis.

\section{Number of Prescriptions Dispensed}

Number of prescriptions dispensed is a variable that was created and was defined as the highest frequency of the number of prescriptions for CDS dispensed that overlap in a 60 day window for the six months prior to the last CDS dispensed. It was created with the variables date filled, pharmacy DEA, and unique ID which can all be found from the CSMP. Number of prescriptions dispensed is a continuous variable for the logistic regression models in the study. It was also used to create a categorical variable, number of prescriptions dispensed, which consists of one prescription, two prescriptions, three prescriptions, and four or more prescriptions.

\section{Drug Name}

Drug name was already a variable included in the CSMP. It contains the name of the drugs dispensed to subjects. The drug names from the CSMP were converted from the NDC by the CSMP before the researchers received the data. Drug name was used to create the variable number of different CDS dispensed. Drug name itself as a variable was not used in analysis.

\section{Number of Different CDS Dispensed}

Number of different CDS dispensed was created as a categorical variable which consists of single CDS, two different CDS, and three or more different CDS. Number of different CDS dispensed was defined as the highest frequency of drug overlap in a 60 day window for the six months prior to the last CDS prescription dispensed. Number of different CDS dispensed was created by using the variables date filled, drug name, and unique ID which can all be found from the CSMP. 


\section{Variables used in Objective 4}

\section{Unique ID}

Unique ID was used to differentiate subjects in the FDD. It was not used to identify subjects in the results. All results were reported in aggregate.

\section{CDS Prescription Verification}

CDS prescription verification was created as a dichotomous variable to identify the verified and the non-verified groups. (See Study Sample for Objective 4 for a description of these two groups.) Age

Age is a continuous variable contained in the FDD. Age was used to create the categorical variable age group. Age was included as a continuous variable in the logistic regression model. Age Group

Age group was created as a categorical variable, which consists of six groups: 18-24, 25-34, 35$44,45-54,55-64$, and $\geq 65$. Age group was used as a variable in the bivariate analyses.

\section{Drug Name}

Drug name was a variable included in the FDD. It contains the name of the drugs detected upon autopsy. Drug name was used to create the variable number of different CDS dispensed. Drug name itself as a variable was not used in analysis.

\section{Number of Different CDS Detected at Autopsy}

Number of different CDS detected at autopsy was created as a categorical variable which consists of a single CDS, two different CDS, and three or more different CDS. Number of different CDS detected at autopsy was defined as the number of different CDS detected upon autopsy. Number of different CDS at autopsy was created by using the variables drug name and unique ID which can be found from the FDD. 


\section{Gender}

Gender was a variable included in the FDD.

See Appendix A for a code book for the variables.

\section{Analysis of Objectives 1-3}

The analysis for the study was conducted using SAS 9.0. Simple descriptive statistics were conducted to determine frequencies and percentages. Frequencies were reported for the following variables: life status, age group, doctor shopping, pharmacy shopping, number of different CDS dispensed, and number of prescriptions dispensed.

Bivariate analyses using the Pearson chi-square statistic were conducted to compare differences in proportion of subjects classified on shopping status by life status. Among subjects classified as doctor shoppers, differences in percentages were compared between life status by age group, pharmacy shopping, number of different CDS dispensed, and number of prescriptions dispensed. The proportion of subjects who are living and those who are deceased who pharmacy shopped were compared by age group, doctor shopping, number of different CDS dispensed, and number of prescriptions dispensed.

Logistic regression was conducted to predict the odds of doctor shopping, pharmacy shopping, and dying related to CDS use. Age, number of different CDS dispensed, and number of prescriptions dispensed were used as predictor variables for each of the logistic regression equations for doctor shopping, pharmacy shopping, and dying related to CDS use. The logistic regression equations for doctor and pharmacy shopping also included life status as a predictor variable. Number of pharmacies was included in the logistic regression to predict doctor shopping; number of doctors was included in the logistic regression to predict pharmacy shopping, and both number of doctors and number of pharmacies as variables were included in the logistic regression equation to predict death related to CDS use. 


\section{Specific Analysis by Objective}

Analysis 1: Frequencies were reported for those who doctor shopped and those that did not further stratified by life status for age group, pharmacy shopping, number of different CDS dispensed, and number of prescriptions dispensed.

Analysis 1a: Bivariate analyses (chi-square) were conducted comparing the proportion of subjects who doctor shopped versus those who did not based on life status.

Analysis $1 b$ : Bivariate analyses (chi-square) were conducted comparing the proportion of subjects classified as doctor shoppers who are living and who are deceased by age group, pharmacy shopping, number of different CDS dispensed, and number of prescriptions dispensed.

Analysis 1c: A logistic regression was conducted to predict the odds of doctor shopping controlling for life status, age, number of different CDS dispensed, number of prescriptions dispensed, and number of pharmacies.

Analysis 2: Frequencies were reported for those who pharmacy shopped and those who did not further stratified by life status for age group, doctor shopping, number of different CDS dispensed, and number of prescriptions dispensed.

Analysis 2a: Bivariate analyses (chi-square) were conducted comparing the proportion of subjects who pharmacy shopped versus those who did not based on life status.

Analysis $2 b$ : Bivariate analyses (chi-square) were conducted comparing the proportion of subjects classified as pharmacy shoppers who are living and who are deceased by age group, pharmacy shopping, number of different CDS dispensed, and number of prescriptions dispensed.

Analysis 2c: A logistic regression was conducted to predict the odds of pharmacy shopping controlling for life status, age, number of different CDS dispensed, number of prescriptions dispensed, and number of doctors. 
Analysis 3: A logistic regression was conducted to predict the odds of dying related to the use of CDS controlling for age, number of different CDS dispensed, number of prescriptions dispensed, number of pharmacies, and number of doctors.

\section{Analysis of Objective 4}

The analysis for the study was conducted using SAS 9.0. Simple descriptive statistics were conducted to determine frequencies and percentages. Frequencies were reported for the following variables: CDS prescription verification groups, age group, number of different CDS at autopsy, and gender.

Bivariate statistics using Pearson chi-square analysis were conducted to compare differences in proportion of deceased subjects with verified prescriptions versus not having all verified prescriptions by demographic groups. The proportion of subjects in the verified group and the non-verified group were compared by age group, number of different CDS at autopsy, and gender.

Logistic regression was conducted to predict the odds of having a CDS prescription for each CDS detected at autopsy. Age, number of different CDS at autopsy, and gender were used as predictor variables in the logistic regression equation.

\section{Specific Analysis by Objective}

Analysis 4: Frequencies of subjects in the CDS prescription verification groups were conducted for the following variables: age group, number of different CDS at autopsy, and gender.

Analysis 4a: Bivariate Analyses (chi-square) were conducted comparing the proportion of subjects in the verified group and the non-verified group by number of different CDS at autopsy and gender.

Analysis 4b: Logistic regression was conducted to predict odds associated with CDS prescription verification controlling for age, number of different CDS (autopsy), and gender. 


\title{
Chapter 4
}

\author{
Results
}

\section{Objectives 1-3}

The West Virginia Controlled Substance Monitoring Program contained 1,055,962 subjects from

July 1, 2005 to December 31, 2007. Of these there were 698 subjects who were also found in the Forensic Drug Database and were therefore considered to be in the deceased group. The remaining 1, 055,264 subjects were considered to be in the living group. Approximately $25.36 \%$ of deceased subjects and $3.61 \%$ of living subjects were doctor shoppers. Approximately $17.91 \%$ of deceased subjects and $1.31 \%$ of living subjects were pharmacy shoppers. Of the living subjects $52.56 \%$ had only one prescription dispensed in the previous six months from the last fill date, whereas $57.88 \%$ of deceased patients had four or more prescriptions dispensed. Approximately $49 \%$ of deceased subjects had three or more different controlled drug substances (CDS); however, $70.99 \%$ of living subjects had only a single CDS in the six months prior to the last fill date. Additional descriptive data are presented in Table 1. 


\begin{tabular}{|c|c|c|c|}
\hline \multicolumn{4}{|c|}{$\begin{array}{l}\text { Table } 1 \\
\text { Descriptives by LifeStatus }\end{array}$} \\
\hline & $\begin{array}{c}\text { Living } \\
1,055,264(99.93) \\
N(\%)\end{array}$ & $\begin{array}{c}\text { Deceased } \\
698(0.07) \\
\text { N (\%) }\end{array}$ & $\begin{array}{c}\text { Total } \\
1,055,962 \\
\mathrm{~N}(\%)\end{array}$ \\
\hline \multicolumn{4}{|l|}{ Age Group } \\
\hline $18-24$ & $102866(9.75)$ & 59 (8.45) & $102925(9.75)$ \\
\hline $25-34$ & $172576(16.35)$ & $158(22.64)$ & $172734(16.36)$ \\
\hline $35-44$ & $182662(17.31)$ & $192(27.51)$ & $182854(17.32)$ \\
\hline $45-54$ & $201794(19.12)$ & $226(32.38)$ & $202020(19.13)$ \\
\hline $55-64$ & $167377(15.86)$ & $54(7.74)$ & $167431(15.86)$ \\
\hline $65+$ & $227989(21.60)$ & $9(1.29)$ & $227998(21.59)$ \\
\hline Doctor Shoppers & $38120(3.61)$ & $177(25.36)$ & $38297(3.63)$ \\
\hline Pharmacy Shoppers & $13807(1.31)$ & $125(17.91)$ & $13932(1.32)$ \\
\hline \multicolumn{4}{|c|}{ Number of Prescriptions Dispensed } \\
\hline 1 Prescription & $554626(52.56)$ & $118(16.91)$ & $554744(52.53)$ \\
\hline 2 Prescriptions & $210814(19.98)$ & $65(9.31)$ & 210879(19.97) \\
\hline 3 Prescriptions & $141078(13.37)$ & $111(15.90)$ & $141189(13.37)$ \\
\hline 4 or more Prescriptions & $148746(14.10)$ & $404(57.88)$ & $149150(14.12)$ \\
\hline \multicolumn{4}{|c|}{ Number of Different CDS Dispensed } \\
\hline Single CDS & 749141 (70.99) & $180(25.79)$ & $749321(70.96)$ \\
\hline 2 CDS & $206113(19.53)$ & $176(25.21)$ & $206289(19.54)$ \\
\hline 3 or more CDS & $100010(9.48)$ & $342(49.00)$ & $100352(9.50)$ \\
\hline
\end{tabular}

Objective 1: Doctor Shopping

Table 2 summarizes the characteristics and comparisons of Doctor Shopping. Doctor shoppers

had a significantly higher proportion of deceased subjects $(0.46 \%)$ compared to non-doctor shoppers

(0.05\%) $\left(X^{2}=943.7262, p<.0001\right)$. Overall, doctor shoppers had significantly higher proportion of

subjects aged $25-34$ (22.41\% vs. $16.13 \%), 35-44$ (20.25\% vs. $17.21 \%)$, and $45-54$ (19.89\% vs. $19.10 \%)$

compared to non-doctor shoppers who had significantly higher proportion of subjects aged 18-24

(9.79\% vs. $8.50 \%), 55-64(15.95 \%$ vs. $13.38 \%)$, and $65+(21.82 \%$ vs. $15.57 \%)\left(X^{2}=1984.1143, p<.0001\right)$.

Doctor shoppers had a significantly higher proportion of subjects who pharmacy shopped (20.31\%)

compared to non-doctor shoppers $(0.60 \%)\left(X^{2}=110072, p<.0001\right)$. Doctor shoppers had significantly

higher proportion of subjects who had three prescriptions dispensed (15.27\% vs. $13.30 \%)$ and four or

more prescriptions dispensed (79.40\% vs. $11.67 \%$ ) compared to non-doctor shoppers who had

significantly higher proportion of subjects who had one prescription dispensed ( $54.49 \%$ vs. $0.52 \%)$ and 
two prescriptions dispensed (20.54\% vs. $4.81 \%)\left(X^{2}=145026, p<.0001\right)$. Doctor shoppers had a significantly higher proportion of subjects who had two different CDS dispensed (30.51\% vs. $19.12 \%)$ and three or more different CDS dispensed (60.48\% vs. $7.58 \%)$ compared to non-doctor shoppers who had significantly higher proportion of subjects who only had one CDS dispensed $(73.29 \%$ vs. $9.00 \%)\left(X^{2}=\right.$ $132620, \mathrm{p}<.0001)$.

Deceased doctor shoppers had significantly higher proportions of subjects aged $25-34$ (28.25\% vs. $22.39 \%), 35-44$ ( $25.42 \%$ vs. $20.22 \%$ ), and $45-54$ (32.77\% vs. $19.83 \%)$ compared to living doctor shoppers, who had significantly higher proportions of subjects aged $18-24$ (8.50\% vs. $7.34 \%)$, 55-64 (13.42\% vs. $5.65 \%)$, and $65+(15.64 \%$ vs. $0.56 \%)\left(X^{2}=53.8223, p<.0001\right)$. Deceased doctor shoppers had a significantly higher proportion of subjects who pharmacy shopped (48.02\%) compared to living doctor shoppers $(20.18 \%)\left(X^{2}=84.3802, p<.0001\right)$. Deceased doctor shoppers had significantly higher proportion of subjects who had four or more prescriptions dispensed (91.53\% vs. $79.34 \%)$ compared to living doctor shoppers, who had significantly higher proportion of subjects who had one prescription dispensed (0.52\% vs. $0 \%)$, two prescriptions dispensed (4.82\% vs. $1.69 \%)$, and three prescriptions dispensed $(15.31 \%$ vs. $6.78 \%)\left(X^{2}=16.1979, p<.0001\right)$. Deceased doctor shoppers had a significantly higher proportion of subjects who had three or more different CDS dispensed (81.36\% vs. $60.39 \%)$ compared to living doctor shoppers who had significantly higher proportion of subjects who only had one CDS dispensed (9.03\% vs. $2.82 \%)$ and two different CDS dispensed (30.58\% vs. $15.82 \%)\left(X^{2}=\right.$ $32.9333, \mathrm{p}<.0001)$.

Deceased non-doctor shoppers had significantly higher proportions of subjects aged 25-34 (20.73\% vs. $16.13 \%), 35-44$ (28.21\% vs. $17.20 \%)$, and $45-54$ (32.25\% vs. $19.10 \%)$ compared to living nondoctor shoppers who had significantly higher proportion of subjects aged $18-24$ (9.79\% vs. 8.83\%), 55-64 (15.95\% vs. $8.45 \%)$, and $65+(21.83 \%$ vs. $1.54 \%)\left(X^{2}=207.8708, p<.0001\right)$. Deceased non-doctor shoppers had a significantly higher proportion of subjects who pharmacy shopped (7.68\%) compared to 
living non-doctor shoppers $(0.60 \%)\left(X^{2}=433.8380, p<.0001\right)$. Deceased non-doctor shoppers had significantly higher proportion of subjects who had three prescriptions dispensed (19.00\% vs. $13.30 \%)$ and four or more prescriptions dispensed (46.45\% vs. $11.65 \%)$ compared to living non-doctor shoppers, who had significantly higher proportion of subjects who had one prescription dispensed $(54.51 \%$ vs. $22.65 \%)$ and two prescriptions dispensed $(20.55 \%$ vs. $11.90 \%)\left(X^{2}=669.1302, p<.0001\right)$. Deceased nondoctor shoppers had a significantly higher proportion of subjects who had two different CDS dispensed ( $28.41 \%$ vs. $19.12 \%$ ) and three or more different CDS dispensed (38.00\% vs. $7.57 \%$ ) compared to living non-doctor shoppers, who had significantly higher proportion of subjects who only had one CDS dispensed (73.31\% vs. 33.59\%) $\left(X^{2}=771.5225, p<.0001\right)$. 


\begin{tabular}{|c|c|c|c|c|c|c|}
\hline \multicolumn{7}{|c|}{$\begin{array}{l}\text { Table } 2 \\
\text { Doctor Shopping Characteristics and Comparisons }\end{array}$} \\
\hline & \multicolumn{3}{|c|}{$\frac{\text { Doctor Shoppers }}{\mathrm{N}(\%)}$} & \multicolumn{3}{|c|}{$\frac{\text { Non-Doctor Shoppers }}{\mathrm{N}(\%)}$} \\
\hline $\begin{array}{l}X^{2}=943.7262 \\
p<.0001\end{array}$ & $\begin{array}{c}\text { Living } \\
38120 \text { (99.54) } \\
\end{array}$ & $\begin{array}{l}\text { Deceased } \\
177(0.46) \\
\end{array}$ & $\begin{array}{c}\text { Total } \\
38297 \\
\end{array}$ & $\begin{array}{c}\text { Living } \\
1017144(99.95) \\
\end{array}$ & $\begin{array}{l}\text { Deceased } \\
521(0.05)\end{array}$ & $\begin{array}{c}\text { Total } \\
1017665 \\
\end{array}$ \\
\hline \multicolumn{7}{|l|}{ Age Group } \\
\hline $\begin{array}{l}x^{2}=1984.1143 \\
p<.0001\end{array}$ & \multicolumn{2}{|c|}{$X^{2}=53.8223, p<.0001$} & & \multicolumn{2}{|c|}{$x^{2}=207.8708, p<.0001$} & \\
\hline $18-24$ & $\begin{array}{r}3241 \\
(8.50) \\
\end{array}$ & $\begin{array}{r}13 \\
(7.34) \\
\end{array}$ & $\begin{array}{r}3254 \\
(8.50) \\
\end{array}$ & $\begin{array}{r}99625 \\
(9.79) \\
\end{array}$ & $\begin{array}{r}46 \\
(8.83) \\
\end{array}$ & $\begin{array}{r}99671 \\
(9.79) \\
\end{array}$ \\
\hline $25-34$ & $\begin{array}{r}8534 \\
(22.39) \\
\end{array}$ & $\begin{array}{r}50 \\
(28.25) \\
\end{array}$ & $\begin{array}{r}8584 \\
(22.41) \\
\end{array}$ & $\begin{array}{l}164042 \\
(16.13) \\
\end{array}$ & $\begin{array}{r}108 \\
(20.73) \\
\end{array}$ & $\begin{array}{l}164150 \\
(16.13)\end{array}$ \\
\hline $35-44$ & $\begin{array}{r}7709 \\
(20.22) \\
\end{array}$ & $\begin{array}{r}45 \\
(25.42) \\
\end{array}$ & $\begin{array}{r}7754 \\
(20.25) \\
\end{array}$ & $\begin{array}{l}174953 \\
(17.20)\end{array}$ & $\begin{array}{r}147 \\
(28.21) \\
\end{array}$ & $\begin{array}{l}175100 \\
(17.21) \\
\end{array}$ \\
\hline $45-54$ & $\begin{array}{r}7559 \\
(19.83) \\
\end{array}$ & $\begin{array}{r}58 \\
(32.77) \\
\end{array}$ & $\begin{array}{r}7617 \\
(19.89) \\
\end{array}$ & $\begin{array}{l}194235 \\
(19.10) \\
\end{array}$ & $\begin{array}{r}168 \\
(32.25) \\
\end{array}$ & $\begin{array}{l}194403 \\
(19.10) \\
\end{array}$ \\
\hline $55-64$ & $\begin{array}{r}5114 \\
(13.42) \\
\end{array}$ & $\begin{array}{r}10 \\
(5.65) \\
\end{array}$ & $\begin{array}{r}5124 \\
(13.38) \\
\end{array}$ & $\begin{array}{l}162263 \\
(15.95)\end{array}$ & $\begin{array}{r}44 \\
(8.45) \\
\end{array}$ & $\begin{array}{l}162307 \\
(15.95)\end{array}$ \\
\hline $65+$ & $\begin{array}{r}5963 \\
(15.64) \\
\end{array}$ & $\begin{array}{r}1 \\
(0.56) \\
\end{array}$ & $\begin{array}{r}5964 \\
(15.57) \\
\end{array}$ & $\begin{array}{l}222026 \\
(21.83) \\
\end{array}$ & $\begin{array}{r}8 \\
(1.54) \\
\end{array}$ & $\begin{array}{l}222034 \\
(21.82) \\
\end{array}$ \\
\hline \multicolumn{7}{|l|}{ Pharmacy Shopping } \\
\hline $\mathrm{X}^{2}=110072, \mathrm{p}<.0001$ & \multicolumn{2}{|c|}{$X^{2}=84.3802, p<.0001$} & & \multicolumn{2}{|c|}{$X^{2}=433.8380, p<.0001$} & \\
\hline Pharmacy Shoppers & $\begin{array}{r}7693 \\
(20.18) \\
\end{array}$ & $\begin{array}{r}85 \\
(48.02) \\
\end{array}$ & $\begin{array}{r}7778 \\
(20.31) \\
\end{array}$ & $\begin{array}{r}6114 \\
(0.60) \\
\end{array}$ & $\begin{array}{r}40 \\
(7.68)\end{array}$ & $\begin{array}{r}6154 \\
(0.60)\end{array}$ \\
\hline Non-Pharmacy Shoppers & $\begin{array}{r}30427 \\
(79.82) \\
\end{array}$ & $\begin{array}{r}92 \\
(51.98) \\
\end{array}$ & $\begin{array}{r}30519 \\
(79.69) \\
\end{array}$ & $\begin{array}{r}1011030 \\
(99.40) \\
\end{array}$ & $\begin{array}{r}481 \\
(92.32) \\
\end{array}$ & $\begin{array}{r}1011511 \\
(99.40) \\
\end{array}$ \\
\hline \multicolumn{7}{|c|}{ Number of Prescriptions Dispensed } \\
\hline $\mathrm{X}^{2}=145026, \mathrm{p}<.0001$ & \multicolumn{2}{|c|}{$x^{2}=16.1979, p=.0010$} & & \multicolumn{2}{|c|}{$X^{2}=669.1302, p<.0001$} & \\
\hline 1 Prescription & $\begin{array}{r}199 \\
(0.52) \\
\end{array}$ & $\begin{array}{r}0 \\
(0.00) \\
\end{array}$ & $\begin{array}{r}199 \\
(0.52) \\
\end{array}$ & $\begin{array}{r}554427 \\
(54.51) \\
\end{array}$ & $\begin{array}{r}118 \\
(22.65) \\
\end{array}$ & $\begin{array}{l}554545 \\
(54.49) \\
\end{array}$ \\
\hline 2 Prescriptions & $\begin{array}{r}1838 \\
(4.82) \\
\end{array}$ & $\begin{array}{r}3 \\
(1.69) \\
\end{array}$ & $\begin{array}{r}1841 \\
(4.81) \\
\end{array}$ & $\begin{array}{r}208976 \\
(20.55) \\
\end{array}$ & $\begin{array}{r}62 \\
(11.90) \\
\end{array}$ & $\begin{array}{l}209038 \\
(20.54) \\
\end{array}$ \\
\hline 3 Prescriptions & $\begin{array}{r}5837 \\
(15.31) \\
\end{array}$ & $\begin{array}{r}12 \\
(6.78) \\
\end{array}$ & $\begin{array}{r}5849 \\
(15.27) \\
\end{array}$ & $\begin{array}{l}135241 \\
(13.30) \\
\end{array}$ & $\begin{array}{r}99 \\
(19.00) \\
\end{array}$ & $\begin{array}{l}135340 \\
(13.30) \\
\end{array}$ \\
\hline 4 or more Prescriptions & $\begin{array}{r}30246 \\
(79.34) \\
\end{array}$ & $\begin{array}{r}162 \\
(91.53) \\
\end{array}$ & $\begin{array}{r}30408 \\
(79.40) \\
\end{array}$ & $\begin{array}{l}118500 \\
(11.65) \\
\end{array}$ & $\begin{array}{r}242 \\
(46.45) \\
\end{array}$ & $\begin{array}{l}118742 \\
(11.67) \\
\end{array}$ \\
\hline \multicolumn{7}{|c|}{ Number of Different CDS Dispensed } \\
\hline $\mathrm{X}^{2}=132620, p<.0001$ & \multicolumn{2}{|c|}{$X^{2}=32.9333, p<.0001$} & & \multicolumn{2}{|c|}{$x^{2}=771.5225, p<.0001$} & \\
\hline $1 \mathrm{CDS}$ & $\begin{array}{r}3443 \\
(9.03) \\
\end{array}$ & $\begin{array}{r}5 \\
(2.82) \\
\end{array}$ & $\begin{array}{r}3448 \\
(9.00) \\
\end{array}$ & $\begin{array}{r}745698 \\
(73.31) \\
\end{array}$ & $\begin{array}{r}175 \\
(33.59) \\
\end{array}$ & $\begin{array}{l}745873 \\
(73.29) \\
\end{array}$ \\
\hline $2 \mathrm{CDS}$ & $\begin{array}{r}11658 \\
(30.58) \\
\end{array}$ & $\begin{array}{r}28 \\
(15.82) \\
\end{array}$ & $\begin{array}{r}11686 \\
(30.51) \\
\end{array}$ & $\begin{array}{l}194455 \\
(19.12) \\
\end{array}$ & $\begin{array}{r}148 \\
(28.41) \\
\end{array}$ & $\begin{array}{l}194603 \\
(19.12) \\
\end{array}$ \\
\hline 3 or more CDS & $\begin{array}{r}23019 \\
(60.39) \\
\end{array}$ & $\begin{array}{r}144 \\
(81.36) \\
\end{array}$ & $\begin{array}{r}23163 \\
(60.48) \\
\end{array}$ & $\begin{array}{l}76991 \\
(7.57) \\
\end{array}$ & $\begin{array}{r}198 \\
(38.00) \\
\end{array}$ & $\begin{array}{r}77189 \\
(7.58) \\
\end{array}$ \\
\hline
\end{tabular}


The logistic regression results for Doctor Shopping are presented in Table 3. The overall model with five predictors was significant $(p<.001)$ indicating the equation predicted the odds of a subject being classified as a doctor shopper. The odds ratios $(95 \% \mathrm{Cl})$ for individual predictors indicated that those with a higher number of different CDS dispensed had a greater odds of doctor shopping (OR = $1.766 ; 95 \% \mathrm{Cl}=1.745-1.788)$. Subjects with a greater number of prescriptions dispensed had a greater odds of doctor shopping $(\mathrm{OR}=1.351 ; 95 \% \mathrm{Cl}=1.343-1.359)$. Subjects who had prescriptions filled at a greater number of different pharmacies had a greater odds of being a doctor shopper $(O R=2.155 ; 95 \%$ $\mathrm{Cl}=2.128-2.182)$. Age showed that older subjects had a lower odds for doctor shopping $(\mathrm{OR}=0.979$; $95 \% \mathrm{Cl}=0.978-0.980)$. Life status was not a significant predictor of doctor shopping.

\begin{tabular}{|c|c|c|}
\hline \multicolumn{3}{|c|}{$\begin{array}{l}\text { Table } 3 \\
\text { Logistic Regression Model for Doctor Shopping }\end{array}$} \\
\hline Variable & Odds Ratio $(95 \% \mathrm{Cl})$ & $p$ \\
\hline Life Status (1=Deceased) & $0.959(0.748,1.231)$ & 0.7431 \\
\hline Age & $0.979(0.978,0.980)$ & $<.0001$ \\
\hline Number of Different CDS Dispensed & $1.766(1.745,1.788)$ & $<.0001$ \\
\hline Number of Prescriptions Dispensed & $1.351(1.343,1.359)$ & $<.0001$ \\
\hline Number of Pharmacies & $2.155(2.128,2.182)$ & $<.0001$ \\
\hline \multicolumn{3}{|c|}{$X^{2}(n=1055962)=119425.493, p<.0001$} \\
\hline \multicolumn{3}{|c|}{$\begin{array}{l}\text { Mean (SD): } \\
\text { Age } 49.01 \text { (18.68); } \\
\text { Number of Different CDS Dispensed } 1.44(0.84) ; \\
\text { Number of Prescriptions Dispensed } 2.11(1.75) ; \\
\text { Number of Pharmacies } 1.23(0.62)\end{array}$} \\
\hline
\end{tabular}

\section{Objective 2: Pharmacy Shopping}

Table 4 summarizes the characteristics and comparisons for Pharmacy Shopping. Pharmacy shoppers had a significantly higher proportion of deceased subjects $(0.90 \%)$ compared to non-pharmacy shoppers $(0.05 \%)\left(X^{2}=1476.3283, p<.0001\right)$. Overall, pharmacy shoppers had significantly higher proportion of subjects aged $25-34$ ( $28.42 \%$ vs. $16.20 \%), 35-44$ ( $23.36 \%$ vs. $17.24 \%)$, and $45-54$ (19.63\% vs. $19.12 \%)$ compared to non-pharmacy shoppers who had significantly higher proportion of subjects aged $18-24$ (9.75\% vs. $9.50 \%), 55-64$ (15.94\% vs. $9.60 \%)$, and $65+(21.75 \%$ vs. $9.49 \%)\left(X^{2}=2863.9939, p\right.$ $<.0001)$. Pharmacy shoppers had a significantly higher proportion of subjects who doctor shopped 
(55.83\%) compared to non-pharmacy shoppers $(2.93 \%)\left(X^{2}=110072, p<.0001\right)$. Pharmacy shoppers had a significantly higher proportion of subjects who had four or more prescriptions dispensed (87.27\% vs. $13.15 \%)$ compared to non-pharmacy shoppers who had significantly higher proportions of subjects who had one prescription dispensed ( $53.23 \%$ vs. $0.29 \%)$, two prescriptions dispensed $(20.20 \%$ vs. $2.45 \%)$, and three prescriptions dispensed (13.42\% vs. 9.98\%) $\left(X^{2}=63110.3184, p<.0001\right)$. Pharmacy shoppers had a significantly higher proportion of subjects who had two different CDS dispensed (25.83\% vs. $19.45 \%)$ and three or more different CDS dispensed (65.10\% vs. $8.76 \%$ ) compared to non-pharmacy shoppers who had significantly higher proportion of subjects who only had one CDS dispensed (71.79\% vs. $9.07 \%)\left(X^{2}=53829.3926, p<.0001\right)$.

Deceased pharmacy shoppers had significantly higher proportions of subjects aged 35-44 ( $29.60 \%$ vs. $23.31 \%)$ and $45-54$ ( $36.00 \%$ vs. $19.48 \%)$ compared to living pharmacy shoppers, who had significantly higher proportions of subjects aged $18-24$ (9.52\% vs. $6.40 \%), 25-34$ ( $28.46 \%$ vs. $24.00 \%), 55-$ $64(9.65 \%$ vs. $3.20 \%)$, and $65+(9.57 \%$ vs. $0.80 \%)\left(X^{2}=36.8703, p<.0001\right)$. Deceased pharmacy shoppers had a significantly higher proportion of subjects who doctor shopped (68.00\%) compared to living pharmacy shoppers $(55.72 \%)\left(X^{2}=7.5775, p=.0059\right)$. Deceased pharmacy shoppers and living pharmacy shoppers did not differ significantly in regard to number of prescriptions dispensed $\left(X^{2}=\right.$ 5.8993, $\mathrm{p}=.1166)$. Deceased pharmacy shoppers had a significantly higher proportion of subjects who had three or more different CDS dispensed (86.40\% vs. $64.91 \%)$ compared to living pharmacy shoppers, who had significantly higher proportion of subjects who only had one CDS dispensed (9.14\% vs. $1.60 \%)$ and two different CDS dispensed (25.95\% vs. $12.00 \%)\left(X^{2}=25.8870, p<.0001\right)$.

Deceased non-pharmacy shoppers had significantly higher proportion of subjects aged 25-34 ( $22.34 \%$ vs. $16.19 \%), 35-44$ ( $27.05 \%$ vs. $17.23 \%)$, and $45-54$ (31.59\% vs. $19.12 \%)$ compared to living nonpharmacy shoppers who had significantly higher proportion of subjects aged $18-24$ (9.75\% vs. 8.90\%), $55-64(15.94 \%$ vs. $8.73 \%)$, and $65+(21.76 \%$ vs. $1.40 \%)\left(X^{2}=220.3250, p<.0001\right)$. Deceased non- 
pharmacy shoppers had a significantly higher proportion of subjects who doctor shopped (16.06\%) compared to living non-pharmacy shoppers $(2.92 \%)\left(X^{2}=347.4937, p<.0001\right)$. Deceased non-pharmacy shoppers had significantly higher proportions of subjects who had three prescriptions dispensed (18.32\% vs. $13.41 \%)$ and four or more prescriptions dispensed ( $49.91 \%$ vs. $13.13 \%)$ compared to living non-pharmacy shoppers, who had significantly higher proportions of subjects with one prescription dispensed (53.25\% vs. $20.59 \%)$ and two prescriptions dispensed $(20.21 \%$ vs. $11.17 \%)\left(X^{2}=737.6915, p\right.$ $<.0001)$. Deceased non-pharmacy shoppers had a significantly higher proportion of subjects who had two different CDS dispensed (28.10\% vs. $19.45 \%)$ and three or more different CDS dispensed (40.84\% vs. 8.74\%) compared to living non-pharmacy shoppers, who had significantly higher proportion of subjects with one CDS dispensed (71.81\% vs. $31.06 \%)\left(X^{2}=827.9122, p<.0001\right)$. 


\begin{tabular}{|c|c|c|c|c|c|c|}
\hline \multicolumn{7}{|c|}{$\begin{array}{l}\text { Table } 4 \\
\text { Pharmacy Shopping Characteristics and Comparisons }\end{array}$} \\
\hline \multirow[b]{2}{*}{$\begin{array}{l}X^{2}=1476.3283 \\
p<.0001\end{array}$} & \multicolumn{3}{|c|}{$\frac{\text { Pharmacy Shoppers }}{\mathrm{N}(\%)}$} & \multicolumn{3}{|c|}{$\frac{\text { Non-Pharmacy Shoppers }}{\mathrm{N}(\%)}$} \\
\hline & $\begin{array}{l}\text { Living } \\
13807 \\
(99.10) \\
\end{array}$ & $\begin{array}{c}\text { Deceased } \\
125 \\
(0.90) \\
\end{array}$ & $\begin{array}{l}\text { Total } \\
14197\end{array}$ & $\begin{array}{c}\text { Living } \\
1041457 \\
(99.95) \\
\end{array}$ & $\begin{array}{c}\text { Deceased } \\
573 \\
(0.05) \\
\end{array}$ & $\begin{array}{l}\text { Total } \\
1042030\end{array}$ \\
\hline \multicolumn{7}{|l|}{ Age Group } \\
\hline $\begin{array}{l}X^{2}=2863.9939 \\
p<.0001\end{array}$ & \multicolumn{2}{|c|}{$x^{2}=36.8703, p<.0001$} & & \multicolumn{2}{|c|}{$x^{2}=220.3250, p<.0001$} & \\
\hline $18-24$ & $\begin{array}{r}1315 \\
(9.52)\end{array}$ & $\begin{array}{r}8 \\
(6.40)\end{array}$ & $\begin{array}{r}1323 \\
(9.50)\end{array}$ & $\begin{array}{r}101551 \\
(9.75) \\
\end{array}$ & $\begin{array}{r}51 \\
(8.90)\end{array}$ & $\begin{array}{r}101602 \\
(9.75) \\
\end{array}$ \\
\hline $25-34$ & $\begin{array}{r}3930 \\
(28.46) \\
\end{array}$ & $\begin{array}{r}30 \\
(24.00) \\
\end{array}$ & $\begin{array}{r}3960 \\
(28.42) \\
\end{array}$ & $\begin{array}{l}168646 \\
(16.19)\end{array}$ & $\begin{array}{r}128 \\
(22.34) \\
\end{array}$ & $\begin{array}{l}168774 \\
(16.20)\end{array}$ \\
\hline $35-44$ & $\begin{array}{r}3218 \\
(23.31) \\
\end{array}$ & $\begin{array}{r}37 \\
(29.60) \\
\end{array}$ & $\begin{array}{r}3255 \\
(23.36) \\
\end{array}$ & $\begin{array}{l}179444 \\
(17.23)\end{array}$ & $\begin{array}{r}155 \\
(27.05) \\
\end{array}$ & $\begin{array}{l}179599 \\
(17.24) \\
\end{array}$ \\
\hline $45-54$ & $\begin{array}{r}2690 \\
(19.48) \\
\end{array}$ & $\begin{array}{r}45 \\
(36.00) \\
\end{array}$ & $\begin{array}{r}2735 \\
(19.63) \\
\end{array}$ & $\begin{array}{l}199104 \\
(19.12) \\
\end{array}$ & $\begin{array}{r}181 \\
(31.59) \\
\end{array}$ & $\begin{array}{l}199285 \\
(19.12) \\
\end{array}$ \\
\hline $55-64$ & $\begin{array}{r}1333 \\
(9.65)\end{array}$ & $\begin{array}{r}4 \\
(3.20)\end{array}$ & $\begin{array}{r}1337 \\
(9.60)\end{array}$ & $\begin{array}{l}166044 \\
(15.94)\end{array}$ & $\begin{array}{r}50 \\
(8.73)\end{array}$ & $\begin{array}{l}166094 \\
(15.94)\end{array}$ \\
\hline $65+$ & $\begin{array}{r}1321 \\
(9.57) \\
\end{array}$ & $\begin{array}{r}1 \\
(0.80) \\
\end{array}$ & $\begin{array}{r}1322 \\
(9.49) \\
\end{array}$ & $\begin{array}{l}226668 \\
(21.76) \\
\end{array}$ & $\begin{array}{r}8 \\
(1.40) \\
\end{array}$ & $\begin{array}{l}226676 \\
(21.75) \\
\end{array}$ \\
\hline \multicolumn{7}{|l|}{ Doctor Shopping } \\
\hline $\begin{array}{l}X^{2}=110072 \\
p<.0001\end{array}$ & \multicolumn{2}{|c|}{$x^{2}=7.5775, p=.0059$} & & \multicolumn{2}{|c|}{$x^{2}=347.4937, p<.0001$} & \\
\hline Doctor Shoppers & $\begin{array}{r}7693 \\
(55.72) \\
\end{array}$ & $\begin{array}{r}85 \\
(68.00) \\
\end{array}$ & $\begin{array}{r}7778 \\
(55.83) \\
\end{array}$ & $\begin{array}{l}30427 \\
(2.92) \\
\end{array}$ & $\begin{array}{r}92 \\
(16.06) \\
\end{array}$ & $\begin{array}{l}30519 \\
(2.93) \\
\end{array}$ \\
\hline Non-Doctor Shoppers & $\begin{array}{r}6114 \\
(44.28) \\
\end{array}$ & $\begin{array}{r}40 \\
(32.00)\end{array}$ & $\begin{array}{r}6154 \\
(44.17)\end{array}$ & $\begin{array}{r}1011030 \\
(97.08)\end{array}$ & $\begin{array}{r}481 \\
(83.94)\end{array}$ & $\begin{array}{r}1011511 \\
(97.07)\end{array}$ \\
\hline \multicolumn{7}{|c|}{ Number of Prescriptions Dispensed } \\
\hline $\begin{array}{l}x^{2}=63110.3184 \\
p<.0001\end{array}$ & \multicolumn{2}{|c|}{$x^{2}=5.8993, p=.1166$} & & \multicolumn{2}{|c|}{$X^{2}=737.6915, p<.0001$} & \\
\hline 1 Prescription & $\begin{array}{r}41 \\
(0.30)\end{array}$ & $\begin{array}{r}0 \\
(0.00)\end{array}$ & $\begin{array}{r}41 \\
(0.29)\end{array}$ & $\begin{array}{l}554585 \\
(53.25) \\
\end{array}$ & $\begin{array}{r}118 \\
(20.59) \\
\end{array}$ & $\begin{array}{l}554703 \\
(53.23) \\
\end{array}$ \\
\hline 2 Prescriptions & $\begin{array}{r}340 \\
(2.46)\end{array}$ & $\begin{array}{r}1 \\
(0.80)\end{array}$ & $\begin{array}{r}341 \\
(2.45)\end{array}$ & $\begin{array}{l}210474 \\
(20.21)\end{array}$ & $\begin{array}{r}64 \\
(11.17) \\
\end{array}$ & $\begin{array}{l}210538 \\
(20.20)\end{array}$ \\
\hline 3 Prescriptions & $\begin{array}{r}1385 \\
(10.03) \\
\end{array}$ & $\begin{array}{r}6 \\
(4.80)\end{array}$ & $\begin{array}{r}1391 \\
(9.98) \\
\end{array}$ & $\begin{array}{l}139693 \\
(13.41)\end{array}$ & $\begin{array}{r}105 \\
(18.32) \\
\end{array}$ & $\begin{array}{l}139798 \\
(13.42)\end{array}$ \\
\hline 4 or more Prescriptions & $\begin{array}{r}12041 \\
(87.21) \\
\end{array}$ & $\begin{array}{r}118 \\
(94.40) \\
\end{array}$ & $\begin{array}{r}12159 \\
(87.27) \\
\end{array}$ & $\begin{array}{l}136705 \\
(13.13)\end{array}$ & $\begin{array}{r}286 \\
(49.91) \\
\end{array}$ & $\begin{array}{l}136991 \\
(13.15) \\
\end{array}$ \\
\hline \multicolumn{7}{|c|}{ Number of Different CDS Dispensed } \\
\hline $\begin{array}{l}X^{2}=53829.3926 \\
p<.0001\end{array}$ & \multicolumn{2}{|c|}{$x^{2}=25.8870, p<.0001$} & & \multicolumn{2}{|c|}{$x^{2}=827.9122, p<.0001$} & \\
\hline $1 \mathrm{CDS}$ & $\begin{array}{r}1262 \\
(9.14)\end{array}$ & $\begin{array}{r}2 \\
(1.60)\end{array}$ & $\begin{array}{r}1264 \\
(9.07)\end{array}$ & $\begin{array}{r}747879 \\
(71.81)\end{array}$ & $\begin{array}{r}178 \\
(31.06)\end{array}$ & $\begin{array}{r}748057 \\
(71.79)\end{array}$ \\
\hline $2 \mathrm{CDS}$ & $\begin{array}{r}3583 \\
(25.95) \\
\end{array}$ & $\begin{array}{r}15 \\
(12.00) \\
\end{array}$ & $\begin{array}{r}3598 \\
(25.83)\end{array}$ & $\begin{array}{r}202530 \\
(19.45)\end{array}$ & $\begin{array}{r}161 \\
(28.10) \\
\end{array}$ & $\begin{array}{l}202691 \\
(19.45)\end{array}$ \\
\hline 3 or more CDS & $\begin{array}{r}8962 \\
(64.91)\end{array}$ & $\begin{array}{r}108 \\
(86.40)\end{array}$ & $\begin{array}{r}9070 \\
(65.10)\end{array}$ & $\begin{array}{r}91048 \\
(8.74)\end{array}$ & $\begin{array}{r}234 \\
(40.84)\end{array}$ & $\begin{array}{l}91282 \\
(8.76)\end{array}$ \\
\hline
\end{tabular}


The logistic regression results for Pharmacy Shopping are presented in Table 5. The overall model with five predictors was significant $(p<.001)$ indicating the equation predicted the odds of a subject being classified as a pharmacy shopper. The odds ratios $(95 \% \mathrm{Cl})$ for individual predictors indicated that those with a higher number of different CDS dispensed had a greater odds of pharmacy shopping $(\mathrm{OR}=1.326 ; 95 \% \mathrm{Cl}=1.304-1.349)$. Subjects with a greater number of prescriptions dispensed had a greater odds of pharmacy shopping $(\mathrm{OR}=1.340 ; 95 \% \mathrm{Cl}=1.329-1.350)$. Subjects who visited a greater number of doctors had a greater odds of pharmacy shopping $(\mathrm{OR}=1.849 ; 95 \% \mathrm{Cl}=$ $1.827-1.872)$. Age showed that older subjects had a lower odds for pharmacy shopping $(O R=0.968$; $95 \% \mathrm{Cl}=0.967-0.970)$. Deceased subjects had higher odds of pharmacy shopping $(\mathrm{OR}=2.642 ; 95 \% \mathrm{Cl}=$ $2.014,3.466)$.

\begin{tabular}{|c|c|c|}
\hline \multicolumn{3}{|c|}{$\begin{array}{l}\text { Table } 5 \\
\text { Logistic Regression Model for Pharmacy Shopping }\end{array}$} \\
\hline Variable & $\begin{array}{l}\text { Odds Ratio } \\
(95 \% \mathrm{Cl})\end{array}$ & $p$ \\
\hline Life Status (1=Deceased) & $2.642(2.014,3.466)$ & $<.0001$ \\
\hline Age & $0.968(0.967,0.970)$ & $<.0001$ \\
\hline Number of Different CDS Dispensed & $1.326(1.304,1.349)$ & $<.0001$ \\
\hline Number of Prescriptions Dispensed & $1.340(1.329,1.350)$ & $<.0001$ \\
\hline Number of Doctors & $1.849(1.827,1.872)$ & $<.0001$ \\
\hline \multicolumn{3}{|c|}{$X 2(n=1055962)=57157.8322, p<.0001$} \\
\hline \multicolumn{3}{|c|}{$\begin{array}{l}\text { Mean (SD): } \\
\text { Age } 49.01 \text { (18.68); } \\
\text { Number of Different CDS Dispensed } 1.44 \text { (0.84); } \\
\text { Number of Prescriptions Dispensed } 2.11(1.75) ; \\
\text { Number of Doctors 1.46 (0.92) }\end{array}$} \\
\hline
\end{tabular}

\section{Objective 3: Controlled Drug Substance Use Mortality}

The logistic regression results for Life Status are presented in Table 6. The overall model with five predictors was significant $(p<.001)$ indicating the equation predicted the odds of dying related to CDS use. The odds ratios $(95 \% \mathrm{Cl})$ for individual predictors indicated that those with a greater number of different CDS dispensed had a higher odds of dying due to CDS use $(\mathrm{OR}=1.581 ; 95 \% \mathrm{Cl}=1.491-$ 1.676). Subjects with a greater number of prescriptions dispensed had a greater odds of dying due to 
$\operatorname{CDS}(\mathrm{OR}=1.110 ; 95 \% \mathrm{Cl}=1.076-1.146)$. Subjects who used more pharmacies had a higher odds of dying related to $\mathrm{CDS}$ use $(\mathrm{OR}=1.288 ; 95 \% \mathrm{Cl}=1.212-1.369)$. Age showed that older subjects had a lower odds of dying related to $\mathrm{CDS}$ use $(\mathrm{OR}=0.967 ; 95 \% \mathrm{Cl}=0.962-0.971)$. Number of doctors was not a significant predictor of the odds of dying related to CDS use.

\begin{tabular}{|c|c|c|}
\hline \multicolumn{3}{|c|}{$\begin{array}{l}\text { Table } 6 \\
\text { Logistic Regression Model for Controlled Drug Substance Mortality }\end{array}$} \\
\hline Variable & Odds Ratio $(95 \% \mathrm{Cl})$ & $p$ \\
\hline Age & $0.967(0.962,0.971)$ & $<.0001$ \\
\hline Number of Different CDS Dispensed & $1.581(1.491,1.676)$ & $<.0001$ \\
\hline Number of Prescriptions Dispensed & $1.110(1.076,1.146)$ & $<.0001$ \\
\hline Number of Pharmacies & $1.288(1.212,1.369)$ & $<.0001$ \\
\hline Number of Doctors & $0.974(0.932,1.018)$ & .2498 \\
\hline \multicolumn{3}{|l|}{$X 2(n=1055962)=1216.1664, p<.0001$} \\
\hline \multicolumn{3}{|l|}{$\begin{array}{l}\text { Mean (SD): } \\
\text { Age 49.01 (18.68); } \\
\text { Number of Different CDS Dispensed } 1.44(0.84) ; \\
\text { Number of Prescriptions Dispensed } 2.11(1.75) ; \\
\text { Number of Pharmacies 1.23 (0.62); } \\
\text { Number of Doctors } 1.46(0.92)\end{array}$} \\
\hline
\end{tabular}

\section{Objective 4: Controlled Drug Substance Prescription Verification}

The Forensic Drug Database contained 944 decedents from July 1, 2005 to December 31, 2007

who had at least one CDS detected upon autopsy. The sample was identified exclusively from the FDD

for this objective. The highest proportions of decedents were aged 25-54. Approximately $65 \%$ of

decedents were male. The majority of decedents had one or two CDS at autopsy. Additional descriptive data are presented in Table 7. 


\begin{tabular}{|l|c|}
\hline $\begin{array}{l}\text { Table } 7 \\
\text { Characteristics of Decedents with at Least One Controlled Drug Substance Detected Upon Autopsy }\end{array}$ \\
\hline & N (\%) \\
\hline Total & $944(100)$ \\
\hline Age Group & $121(12.82)$ \\
\hline $18-24$ & $235(24.89$ \\
\hline $25-34$ & $255(27.01)$ \\
\hline $35-44$ & $267(28.28)$ \\
\hline $45-54$ & $57(6.04)$ \\
\hline $55-64$ & $9(0.95)$ \\
\hline $65+$ & \\
\hline Gender & $617(65.36)$ \\
\hline Male & $327(34.64)$ \\
\hline Female & \\
\hline Number of Different CDS at Autopsy & $414(43.86$ \\
\hline 1 CDS & $351(37.18)$ \\
\hline 2 CDS & $179(18.96)$ \\
\hline 3 or more CDS & \\
\hline
\end{tabular}

Table 8 summarizes the characteristics and comparisons of decedents with regard to CDS Prescription Verification. Of the 944 decedents, 287 (30.40\%) had a verified prescription for all CDS detected upon autopsy whereas 657 (69.60\%) decedents had at least one CDS not verified by a prescription. Decedents without verification for all their CDS prescriptions detected upon autopsy had significantly higher proportion of decedents aged $18-24$ (16.89\% vs. $3.48 \%), 25-34$ (29.68\% vs. $13.94 \%)$, and $35-44$ ( $27.55 \%$ vs. $25.78 \%)$ compared to decedents with verification for all their CDS prescriptions detected upon autopsy, who had significantly higher proportion of decedents aged 45-54 (44.95\% vs. $21.00 \%), 55-64$ (9.76\% vs4.41\%), and $65+(2.09 \%$ vs. $0.46 \%)\left(X^{2}=103.6627, p<.0001\right)$. Decedents without verification for all their CDS prescriptions detected upon autopsy had a significantly higher proportion of decedents who were male (68.95\%) compared to decedents with verification for all their CDS prescriptions detected upon autopsy $(57.14 \%)\left(X^{2}=12.2987, p<.0001\right)$. Decedents without verification for all their CDS prescriptions detected upon autopsy had a significantly higher proportion of decedents who had two different CDS (38.96\% vs. $33.10 \%)$ and three or more different CDS (22.98\% vs. 9.76\%) compared to decedents with verification for all their CDS prescriptions detected upon autopsy, 
who had significantly higher proportion of decedents who only had one CDS (57.14\% vs. $38.05 \%)\left(\mathrm{X}^{2}=\right.$ $36.8774, \mathrm{p}<.0001)$.

\begin{tabular}{|c|c|c|}
\hline \multicolumn{3}{|c|}{$\begin{array}{l}\text { Table } 8 \\
\text { Characteristics and Comparisons of Decedents by Controlled Drug Substance Prescription Verification }\end{array}$} \\
\hline & $\begin{array}{c}\text { All Controlled Drug Substance(s) } \\
\text { Verified by a Prescription } \\
\mathrm{N}(\%) \\
287(30.40)\end{array}$ & $\begin{array}{l}\text { At Least One Controlled Drug Substance Not } \\
\text { Verified by a Prescription } \\
\text { N (\%) } \\
657(69.60)\end{array}$ \\
\hline Age Group & \multicolumn{2}{|l|}{$x^{2}=103.6627, p<.0001$} \\
\hline $18-24$ & $10(3.48)$ & $111(16.89)$ \\
\hline $25-34$ & 40 (13.94) & $195(29.68)$ \\
\hline $35-44$ & $74(25.78)$ & $181(27.55)$ \\
\hline $45-54$ & $129(44.95)$ & $138(21.00)$ \\
\hline $55-64$ & $28(9.76)$ & $29(4.41)$ \\
\hline $65+$ & $6(2.09)$ & $3(0.46)$ \\
\hline Gender & \multicolumn{2}{|l|}{$X^{2}=12.2987, p=.0005$} \\
\hline Male & 164 (57.14) & 453 (68.95) \\
\hline Female & $123(42.86)$ & $204(31.05)$ \\
\hline $\begin{array}{l}\text { Number of Different } \\
\text { CDS at Autopsy }\end{array}$ & \multicolumn{2}{|l|}{$X^{2}=36.8774, p<.0001$} \\
\hline $1 \mathrm{CDS}$ & $164(57.14)$ & $250(38.05)$ \\
\hline $2 \mathrm{CDS}$ & $95(33.10)$ & $256(38.96)$ \\
\hline 3 or more CDS & $28(9.76)$ & $151(22.98)$ \\
\hline
\end{tabular}

Table 9 summarizes the characteristics and comparisons of decedents with at least one CDS not verified by a prescription. Of the 657 decedents who had at least one CDS not verified by a prescription, $185(28.16 \%)$ had at least one verified prescription whereas 427 (71.84\%) did not have a verified prescription for all CDS detected at autopsy. Decedents without prescriptions for all their CDS detected upon autopsy had significantly higher proportion of decedents aged $18-24$ (21.61\% vs. $4.86 \%)$ and $25-34$ (30.93\% vs. 26.49\%) compared to decedents with at least one verified prescription for all their CDS detected upon autopsy, who had significantly higher proportion of decedents aged 35-44 (32.97\% vs. $25.42 \%), 45-54$ (27.57\% vs. $18.43 \%), 55-64$ ( $8.11 \%$ vs. $2.97 \%)$, and $65+(0.00 \%$ vs. $0.64 \%)\left(X^{2}=40.1107, p\right.$ $<.0001)$. Decedents without prescriptions for all their CDS detected upon autopsy and decedents who had at least one verified prescription for all their CDS detected upon autopsy did not differ significantly in regard gender $\left(X^{2}=3.2100, p=.0732\right)$. Among decedents who had two or more CDS detected upon 
autopsy, there was a significantly greater proportion that had at least one verified prescription than those without prescriptions for any of their $\operatorname{CDS}\left(X^{2}=166.1319, p<.0001\right)$.

\begin{tabular}{|c|c|c|}
\hline \multicolumn{3}{|c|}{$\begin{array}{l}\text { Table } 9 \\
\text { Characteristics and Comparisons of Decedents with at Least One Controlled Drug Substance Not Verified } \\
\text { by a Prescription }\end{array}$} \\
\hline & $\begin{array}{l}\text { At Least One Verified Controlled Drug } \\
\text { Substance Prescription } \\
\mathrm{N}(\%) \\
185(28.16)\end{array}$ & $\begin{array}{l}\text { All Controlled Drug Substances Prescriptions } \\
\text { Were Without Verified Prescriptions } \\
\qquad \begin{array}{l}\text { N (\%) } \\
472(71.84)\end{array}\end{array}$ \\
\hline Age Group & \multicolumn{2}{|l|}{$X^{2}=40.1107, p<.0001$} \\
\hline $18-24$ & $9(4.86)$ & $102(21.61)$ \\
\hline $25-34$ & 49 (26.49) & $146(30.93)$ \\
\hline $35-44$ & $61(32.97)$ & $120(25.42)$ \\
\hline $45-54$ & $51(27.57)$ & $87(18.43)$ \\
\hline $55-64$ & $15(8.11)$ & $14(2.97)$ \\
\hline $65+$ & $0(0.00)$ & $3(0.64)$ \\
\hline Gender & \multicolumn{2}{|l|}{$X^{2}=3.2100, p=.0732$} \\
\hline Male & $118(63.78)$ & $335(70.97)$ \\
\hline Female & $67(36.22)$ & $137(29.03)$ \\
\hline $\begin{array}{l}\text { Number of Different } \\
\text { CDS at Autopsy }\end{array}$ & \multicolumn{2}{|l|}{$X^{2}=166.1319, p<.0001$} \\
\hline $1 \mathrm{CDS}$ & $0(0.00)$ & $250(52.97)$ \\
\hline $2 \mathrm{CDS}$ & $104(56.22)$ & $152(32.20)$ \\
\hline 3 or more CDS & $81(43.78)$ & $70(14.83)$ \\
\hline
\end{tabular}

The logistic regression results for CDS Prescription Verification are presented in Table 10. The overall model with three predictors was significant $(p<.001)$ indicating the equation predicted the odds that a decedent had prescriptions for all CDS detected at autopsy. The odds ratios $(95 \% \mathrm{Cl})$ for individual predictors indicated that decedents who had a higher number of different CDS at autopsy had a greater odds of not having a prescription for each CDS detected $(\mathrm{OR}=1.842 ; 95 \% \mathrm{Cl}=1.499-2.264)$. Males had a greater odds of not having a prescription for each CDS detected than females $(O R=1.667$; $95 \% \mathrm{Cl}=1.220-2.277)$. Age showed that older decedents had a lower odds of not having verified prescriptions for all the CDS detected upon autopsy (OR $=0.933 ; 95 \% \mathrm{Cl}=0.919-0.947)$. 


\begin{tabular}{|l|l|l|}
\hline \multicolumn{4}{|l|}{ Table 10} \\
Logistic Regression Model for Controlled Drug Substance Prescription Verification
\end{tabular}




\section{Chapter 5}

\section{Discussion}

\section{Discussion}

The results indicated that there is evidence of both doctor shopping and pharmacy shopping in relation to controlled substances in West Virginia, which was more prominent in deceased than living subjects. Few living subjects were considered doctor shoppers compared to approximately one-quarter of deceased subjects who were considered doctor shoppers. The later finding was in agreement to that from a previous study of the 2006 subset of West Virginia death data where approximately $21 \%$ of deceased prescription drug abusers were considered doctor shoppers. ${ }^{7}$ Pharmacy shopping followed a similar trend as seen with doctor shopping. Only about $1 \%$ of the living subjects were considered pharmacy shoppers. This finding is similar to the Buurma et al. study which found that approximately $2 \%$ of a living cohort used two or more pharmacies. ${ }^{28}$ In contrast, approximately $17 \%$ of deceased subjects were considered pharmacy shoppers. The concern is not only that there is evidence of doctor shopping and pharmacy shopping, but also how they are related.

Approximately $20 \%$ of doctor shoppers were also pharmacy shoppers compared to only $0.6 \%$ of subjects classified as non doctor shoppers. This finding supports a previous finding by Katz et al. that the greater number of providers used, the number of pharmacies used increases. ${ }^{29}$ Moreover, a higher proportion of pharmacy shoppers were also doctor shoppers compared to non pharmacy shoppers. This finding seems logical in that a patient would need to see more doctors in order to go to more pharmacies without appearing to be engaging in suspicious behavior, since a patient cannot get a prescription filled for a controlled drug substance without first seeing a physician. This shows the significance of communication between healthcare providers and the apparent disconnect evident in the healthcare system. 
Two results from the study revealed an interesting finding. The number of doctors was not a significant predictor of the odds of dying related to CDS use, whereas the number of pharmacies was a significant predictor. Additionally, life status was not a predictor of doctor shopping, but it was for pharmacy shopping. These results support that pharmacy shopping is an important target in combating prescription drug abuse. Furthermore, it emphasizes the importance of utilizing prescription monitoring programs and healthcare professionals working together as a team to combat future doctor and pharmacy shopping.

Similar patterns emerged for both doctor shopping and pharmacy shopping in regard to increased utilization of the number of prescriptions dispensed, the number of different controlled drug substances dispensed, and the number of providers. A large proportion of doctor and pharmacy shoppers had four or more prescriptions dispensed. However, this may be overestimating doctor and pharmacy shopping in that living and deceased subjects who have a terminal illness being treated by multiple physicians may be misclassified as shoppers which would reduce the proportion of living and deceased shoppers. Regardless of having legitimate reasons for seeing multiple physicians for treatment of a severe disease, such patients should not be doctor shopping; supporting the importance of a patient-centered medical home.

In pharmacy shopping there was no difference between living and deceased subjects in number of prescriptions dispensed. However, a high percentage of both doctor and pharmacy shoppers had three or more different controlled drug substances dispensed. As well as having increased numbers of prescriptions and controlled drug substances dispensed, the odds of doctor shopping and pharmacy shopping increased as the number of pharmacies and the number of doctors increased, respectively. Furthermore, the number of different controlled drug substances dispensed, the number of different prescriptions, and the number of pharmacies were all significant predictors of dying. 
These increases in utilization of prescriptions, different controlled drug substances, and providers were consistent with previous findings. The number of different doctors seen, number of doctor visitation rates, and the number of prescriptions were found to have peaked the year prior to death in patients who died of a heroin-related overdose. ${ }^{13}$ A study using the California Prescription Monitoring Program also found that with an increase in the number of different controlled drug substances there was an increase in the number of providers as well. Healthcare professionals should identify patients with increased utilization rates through prescription monitoring programs if available to avoid adverse outcomes.

Healthcare professionals should hypervigilantly prescribe/dispense CDS and monitor patients who have been identified with high utilization rates. In the present study the number of pharmacies, and not the number of doctors, was a significant predictor of the odds of dying related to CDS use and provides support for the importance of the role a pharmacist can play working with physicians to identify at risk patients. Tamblyn et al. found that having a single pharmacist as well as a single physician reduced potentially inappropriate drug combinations by $32 \%{ }^{26}$ It is important to note that patient safety is a shared responsibility among healthcare providers. All healthcare professionals should work together utilizing prescription monitoring programs when appropriate to prevent the misuse of controlled drug substances at the same time enhancing patient care.

Among non-shoppers (both doctor and pharmacy), deceased subjects had a higher proportion of three or more CDS than living subjects. This is a concern because although these subjects were not considered shoppers they were still dying due to increased use of multiple CDS. This is related to a study by Bohnert and colleagues. ${ }^{54}$ They found that higher opioid doses were associated with increased risk of death. ${ }^{54}$ This finding along with the findings in the present study that increased number of different CDS and increased number of prescriptions provide evidence that healthcare professionals need to be conscious of these risks when prescribing/dispensing to their patients. 
Although the study did not examine the utilization or effectiveness of the Controlled Substance Monitoring Program, it does support that data captured can be useful to healthcare professionals. Without the use of an up-to-date prescription monitoring program it would be impossible for healthcare professionals to accurately identify the utilization markers; currently it is the only way to objectively identify the use of multiple pharmacies. To receive the full benefit from prescription monitoring programs, they should be current/real time as well as being at a national level and not just focused on an individual state. Abusers may travel to contiguous states to obtain controlled drug substances, especially to states that do not have prescription monitoring programs. ${ }^{42}$ Creating a valuable prescription monitoring program might take a great deal of resources (e.g., time, money, personnel) to keep it running effectively. This cost may be outweighed by the usefulness of the prescription monitoring program. It can also be used to provide better education and programs to healthcare professionals, possibly through proactively sharing routine reports of potential doctor/pharmacy shoppers. Perhaps better counseling, interventions, treatment, and monitoring can be created. Prescription monitoring programs should not only focus on the patient or the doctor; rather the pharmacist should be incorporated as a partner to help create a more unified, effective plan. Prescription monitoring plans have the propensity to save lives if implemented and utilized.

Since approximately $30 \%$ of deceased subjects had a verified prescription for all of the controlled drug substances that were detected upon autopsy, healthcare professionals might have been able to play a role in preventing their death. Healthcare professionals monitoring and emphasizing to patients the importance of following their health provider's instructions appear warranted. Counseling and re-emphasizing to every patient who receives a controlled drug substance that it is important not to take non-prescribed drugs or to share his/her drugs with others due to the potential risk for toxicity and death with those drugs. Unfortunately, around $70 \%$ of deceased subjects had at least one controlled drug substance detected upon autopsy that did not have a verified prescription record for the drug. Of 
these subjects, $30 \%$ had two or more controlled drug substances, which means that they are obtaining at least one of them from the healthcare system where healthcare professionals have a chance to intervene. However, the other $70 \%$ obtained all of their controlled drug substances without prescriptions. If patients are obtaining controlled drug substances from avenues other than through a valid visit to a doctor and a pharmacy, it may be impossible to reach out and intervene to a population that may be more vulnerable for adverse risk.

\section{Limitations}

The study is limited by the use of a secondary database that collected variables for intended purposes other than research. The Controlled Substance Monitoring Program (CSMP) database does not capture how subjects paid for their controlled drug substances (e.g., type of insurance, cash), the subjects' medical conditions the controlled drug substance is treating, any medical records for the subjects, or gender. This limits the amount of questions a researcher can answer using the database. The CSMP only captures data on prescriptions that have been filled for a controlled drug substance (Schedule II through Schedule IV). ${ }^{47}$ From January 1, 2006, Schedule V pseudoephedrine products were required to be reported to the CSMP. ${ }^{47}$ Schedule V pseudoephedrine data were not included in the study, because it could be purchased without a prescription. The data do not ensure that the patient actually picked up the medication and therefore may slightly overestimate doctor and pharmacy shopping. Only prescription drugs dispensed in the state of West Virginia are reported in the CSMP. If a patient lives close to a bordering state he/she may have his/her prescriptions filled in a neighboring state which may underestimate doctor and pharmacy shopping. Government facilities (e.g., VA hospitals) and inpatient hospitals do not report data to the CSMP, which could also underestimate doctor and pharmacy shopping.

The CSMP might have limited the estimate of doctor shopping for two different reasons. First, living and deceased subjects may have been misclassified as doctor shoppers when actually they had a 
severe disease being treated by multiple physicians. Thus, removing these patients would lower the proportion of true doctor shoppers in both the living and deceased groups. Therefore, the true effect size of the difference in shopping rates between the living and deceased groups cannot be determined in this study because of potential misclassification.

Secondly, doctor shopping may have been overestimated because patients may see more than one doctor within the same clinic or practice, causing them to appear to be doctor shoppers even when they are not. Doctor shopping may also be overestimated because a patient may seek out several physicians in an attempt to adequately treat their pain. However, even if there is a team of physicians, either within or outside the same clinic (e.g. a primary care physician, a disease specialist, a pain specialist, and perhaps an addiction specialist) treatment should be coordinated with only one physician prescribing the pain medications. Pharmacists can utilize prescription monitoring programs to monitor multiple controlled drug substance use and communicate with involved prescribers to ensure they are aware of the other prescriptions.

Pharmacy shopping may be overestimated because some patients may get their prescriptions filled at different pharmacies for legitimate reasons, such as convenience, the pharmacy they usually go to may not have the medication in stock, or perhaps their insurance changed and they can only go to certain pharmacies to get their prescriptions. Pharmacy shopping may also be overestimated because patients may go to two different pharmacies in the same chain that share patient profiles, essentially meaning the patient is going to one pharmacy although the CSMP would record it as two different pharmacy DEA numbers.

The conservative definitions (i.e., equal to or greater than four doctors/pharmacies over a six month period) of doctor/pharmacy shopping should minimize the aforementioned reasons for possible overestimations of both doctor shopping and pharmacy shopping. The conservative definitions might in fact reflect an underestimate of both doctor and pharmacy shopping. Patients may also doctor and 
pharmacy shop for non-controlled drug substance abused drugs (e.g., Flexeril ${ }^{\circledR}$ ) not captured by the CSMP. A more liberal definition for both doctor/pharmacy shopping as seeing three or more doctors/pharmacies in a six month period produced robust results; since the findings were similar (data not included) the more conservative definitions were used.

The study did not examine the quantity or strength of the medications. Therefore, three prescriptions for Xanax with a 10-day supply would appear the same as three prescriptions for a 30-day supply. Both would be counted as three prescriptions and one controlled drug substance dispensed.

The generalizability of the study may be limited because only West Virginia data were used. Previous research has shown that West Virginia has a higher rate of prescription drug abuse than the national average. ${ }^{7,12}$ Finally, there was no way to track in the CSMP if patients in the living group were taking additional controlled drug substances for which they do not have a prescription and/or illegal drug use; therefore, the results from the study should not be extrapolated to other drug categories such as non-controlled prescriptions, over-the-counter medications and/or illegal drugs beyond the use of controlled drug substances.

The time to resuscitation is a major limitation of studying unintentional drug overdoses from a database. A subject's personal behaviors and habits, health status, body state especially obesity, and the distance to healthcare services are important factors in regards to resuscitation. These factors are not contained in the FDD or the CSMP.

\section{Future Research}

Additional studies are needed to explore other unanswered questions about the use of prescription monitoring programs. A previous study examined physicians' attitudes towards a prescription monitoring program, ${ }^{16}$ but there is still a need to examine utilization of prescription monitoring programs by pharmacists. Additional studies are needed to explore other unanswered questions about the use/abuse of controlled drug substances including whether a certain pattern exists 
for specific strengths and days supply for certain drugs. This information would help prescription monitoring programs target certain patterns and identify potential patients that could benefit from intervention by a healthcare provider.

While the study only used subjects from West Virginia, future research should examine a broader sample that would include all states that have prescription monitoring programs. Also the FDD is a potential resource for future studies, especially if more states contribute drug-induced and drugrelated death information. As data collection grows over the years in these relatively new electronic databases, trend analysis on controlled drug substance use and drug death could be a valuable research avenue.

Future studies should continue to examine doctor and pharmacy shopping from a healthcare professional's perspective. It is important to include a well representative sample of community pharmacists. As the last healthcare professional that patients see before obtaining their medications, pharmacists should be surveyed to help identify needed resources required to intervene with patients who have a potential to doctor and pharmacy shop.

\section{Conclusion}

In conclusion, there is evidence of doctor shopping and pharmacy shopping for controlled drug substances in West Virginia. One-fifth of doctor shoppers were also pharmacy shoppers, and 55\% of pharmacy shoppers were also doctor shoppers. Factors that predicted odds of being a shopper included: 1) number of prescriptions dispensed; 2) number of different controlled drug substances dispensed; 3) number of physicians visited; and 4) number of pharmacies visited. Pharmacists should play a role in intervening with patients who display these risk factors, as prescription drug diversion/abuse prevention should not be placed on prescribers exclusively. Pharmacists as well as physicians may rely on a prescription monitoring program to identify pharmacy shoppers. An intervention by the pharmacist is important because almost a third of deceased subjects had a verifiable 
Chapter 5: Discussion

prescription for all of their controlled drug substances detected upon autopsy. Utilization of a prescription monitoring program by healthcare professionals as an integrated tool for tracking the prescribing and dispensing of controlled drug substances, as well as its propensity to prevent druginduced and drug related deaths, should be considered. 


\section{References}

1. McCabe SE, Cranford JA, West BT. Trends in prescription drug abuse and dependence, cooccurrence with other substance use disorders, and treatment utilization: results from two national surveys. Addictive Behaviors. Oct 2008;33(10):1297-1305.

2. McCabe SE, West BT, Wechsler H. Trends and college-level characteristics associated with the non-medical use of prescription drugs among US college students from 1993 to 2001. Addiction. Mar 2007;102(3):455-465.

3. Simoni-Wastila L, Strickler G. Risk Factors Associated with Problem Use of Prescription Drugs. American Journal of Public Health. Feb 2004;94(2):266-268.

4. Paulozzi LJ, Budnitz DS, Xi Y. Increasing deaths from opioid analgesics in the United States.[see comment]. Pharmacoepidemiology \& Drug Safety. Sep 2006;15(9):618-627.

5. Joranson DE, Ryan KM, Gilson AM, Dahl JL. Trends in Medical Use and Abuse of Opioid Analgesics. JAMA. 2000;283(13):1710-1714.

6. Adams EH, Breiner S, Cicero TJ, et al. A comparison of the abuse liability of tramadol, NSAIDs, and hydrocodone in patients with chronic pain. Journal of Pain \& Symptom Management. May 2006;31(5):465-476.

7. Hall AJ, Logan JE, Toblin RL, et al. Patterns of abuse among unintentional pharmaceutical overdose fatalities.[see comment]. JAMA. Dec 10 2008;300(22):2613-2620.

8. Services DoHaH. Overview of Findings from 2003 National Survey on Drug Use and Health. 2004; http://oas.samhsa.gov/nhsda/2k3NSDUH/2k3overvieww.pdf.

9. Bollinger L, Bush C, Califano J, et al. Under the Counter. The diversion and abuse of controlled prescription drugs in the USJuly 2005.

10. Studies OoA. The NSDUH Report: Patterns and Trends in Nonmedical Prescription Pain Reliever Use: 2002-2005. 2007; http://www.oas.samhsa.gov/2k7/pain/pain.htm.

11. Maxwell JC. Trends in the abuse of prescription drugs. The Gulf Coast Addiction Technology Transfer Center (GCATTC). 2006.

12. Studies OoA. State Estimates of Substance Use and Mental Health from the 2005-2006 National Surveys on Drug Use and Heath, West Virginia State Profile. 2005-2006; http://oas.samhsa.gov/2k6State/WestVirginia.htm.

13. Martyres RF, Clode D, Burns JM. Seeking drugs or seeking help? Escalating "doctor shopping" by young heroin users before fatal overdose.[see comment]. Medical Journal of Australia. Mar 1 2004;180(5):211-214.

14. Spillane J, McAllister WB. Keeping the lid on: a century of drug regulation and control* 1. Drug and Alcohol Dependence. 2003;70(3):S5-S12.

15. Manchikanti L, Brown KR, Singh V. National All Schedules Prescription Electronic Reporting Act (NASPER): balancing substance abuse and medical necessity. Pain Physician. 2002;5(3):294.

16. Barrett K, Watson A. Physician perspectives on a pilot prescription monitoring program. Journal of Pain \& Palliative Care Pharmacotherapy. 2005;19(3):5-13.

17. Kuehn BM. Opioid prescriptions soar: increase in legitimate use as well as abuse. JAMA. 2007;297(3):249.

18. Inciardi JA, Surratt HL, Kurtz SP, Cicero TJ. Mechanisms of prescription drug diversion among drug-involved club- and street-based populations. Pain Medicine. Mar 2007;8(2):171-183.

19. Jonathan C. How prevalent are "very light" drug users? The FAS Drug Policy Analysis Bulletin 1997;September(3). 
20. Fischer B, Rehm J, Patra J, Firestone Cruz M. Changes in illicit opioid use across Canada. Canadian Medical Association Journal. 2006;175(11):1385.

21. Joranson DE, Gilson AM. Drug crime is a source of abused pain medications in the United States. Journal of pain and symptom management. 2005;30(4):299-301.

22. Manchikanti L, Pampati V, Damron KS, McManus CD. Evaluation of variables in illicit drug use: does a controlled substance abuse screening tool identify illicit drug use? Pain Physician. 2004;7(1):71.

23. Hurwitz W. The challenge of prescription drug misuse: A review and commentary. Pain Medicine. 2005;6(2):152-161.

24. Klienschmidt R, Price J, Caught K. Doctor shopping. Australian Family Physician. Jun 1995;24(6):1037-1041.

25. Pradel V, Thirion X, Ronfle E, Masut A, Micallef J, Begaud B. Assessment of doctor-shopping for high dosage buprenorphine maintenance treatment in a French region: development of a new method for prescription database. Pharmacoepidemiology \& Drug Safety. Jul 2004;13(7):473481.

26. Tamblyn RM, McLeod PJ, Abrahamowicz M, Laprise R. Do too many cooks spoil the broth? Multiple physician involvement in medical management of elderly patients and potentially inappropriate drug combinations. CMAJ: Canadian Medical Association Journal. 1996;154(8):1177.

27. Feroni I, Peretti-Watel P, Paraponaris A, Masut A, Ronfle E, Mabriez JC. French General Practitioners' Attitudes and Prescription Patterns Toward Buprenorphine Maintenance Treatment. Journal of Addictive Diseases. 2005;24(3):7-22.

28. Buurma HPD, Bouvy ML, De Smet P, Floor-Schreudering APD, Leufkens HGM, Egberts ACG. Prevalence and determinants of pharmacy shopping behaviour. Journal of Clinical Pharmacy \& Therapeutics. 2008;33(1):17.

29. Katz N, Panas L, Kim ML, et al. Usefulness of prescription monitoring programs for surveillanceanalysis of Schedule II opioid prescription data in Massachusetts, 1996-2006.

Pharmacoepidemiology and Drug Safety. 2010;19(2):115-123.

30. Hughes GF, McElnay JC, Hughes CM, McKenna P. Abuse/misuse of non-prescription drugs. Pharmacy World \& Science. Dec 1999;21(6):251-255.

31. Chabal C, Erjavec MK, Jacobson L, Mariano A, Chaney E. Prescription opiate abuse in chronic pain patients: clinical criteria, incidence, and predictors. The Clinical journal of pain. 1997;13(2):150.

32. Turk DC, Okifuji A. What factors affect physicians' decisions to prescribe opioids for chronic noncancer pain patients? The Clinical journal of pain. 1997;13(4):330.

33. Manchikanti L, Singh A. Therapeutic opioids: a ten-year perspective on the complexities and complications of the escalating use, abuse, and nonmedical use of opioids. Pain Physician. 2008;11(2 Suppl):S63-S88.

34. Compton WM, Volkow ND. Major increases in opioid analgesic abuse in the United States: concerns and strategies. Drug and Alcohol Dependence. 2006;81(2):103-107.

35. Substance Abuse and Federal entitlement program. New York Columbia University; 1995.

36. Batten H, Prottas J, Horgan Cea. Phase II Final Report. Submitted to the National Institute on Drug Abuse. February 12, 1993; http://www.icpsr.umich.edu/files/SAMHDA/PDF/ot3393p2.pdf.

37. Rice DP, Kelman S, Miller LS. Estimates of economic costs of alcohol and drug abuse and mental illness, 1985 and 1988. Public health reports. 1991;106(3):280.

38. McLellan AT, Lewis DC, O'Brien CP, Kleber HD. Drug dependence, a chronic medical illness: implications for treatment, insurance, and outcomes evaluation. JAMA. 2000;284(13):1689. 
39. Merboth MK, Barnason S. Managing pain: the fifth vital sign. The Nursing clinics of North America. 2000;35(2):375.

40. Fishman SM, Papazian JS, Gonzalez S, Riches PS, Gilson A. Regulating opioid prescribing through prescription monitoring programs: Balancing drug diversion and treatment of pain. Pain Medicine. 2004;5(3):309-324.

41. Gilson AM, Joranson DE. U.S. policies relevant to the prescribing of opioid analgesics for the treatment of pain in patients with addictive disease. Clinical Journal of Pain. Jul-Aug 2002;18(4 Suppl):S91-98.

42. Manchikanti L, Whitfield E, Pallone F. Evolution of the National All Schedules Prescription Electronic Reporting Act (NASPER): A public law for balancing treatment of pain and drug abuse and diversion. Pain Physician. 2005;8(4):335.

43. Prescription Drug Monitoring: Strategies to Promote Treatment and Deter Prescription Drug Use. Hearing before the Subcommittee on Health of the Comm2004:73.

44. Benak LD, Eccher D, McKinney RE, Smith CM. Prescription drug monitoring through the Maine Office of Substance Abuse. Journal of Forensic Nursing. 2008;3(3-4):141-145.

45. Katz N, Houle B, Fernandez KC, et al. Update on prescription monitoring in clinical practice: a survey study of prescription monitoring program administrators. Pain Medicine. Jul-Aug 2008;9(5):587-594.

46. Weissman MM, Johnson J. Drug use and abuse in five US communities. New York state journal of medicine. 1991;91(11 Suppl):19S.

47. Governing, The Practice of Pharmacy, Controlled Substance Act, (2008).

48. Roberts g, moss Ah. Physicians' Perceptions of Doctor Shopping in West Virginia. West Virginia Medical Journal. 2010;May/June.

49. Wilsey BL, Fishman SM, Gilson AM, et al. Profiling multiple provider prescribing of opioids, benzodiazepines, stimulants, and anorectics. Drug and Alcohol Dependence. 2010.

50. Victorri-Vigneau $C$, Basset $G$, Jolliet $P$. How a novel programme for increasing awareness of health professionals resulted in a $14 \%$ decrease in patients using excessive doses of psychotropic drugs in western France. European journal of clinical pharmacology. 2006;62(4):311-316.

51. Simoni-Wastila $L$, Tompkins $C$. Balancing diversion control and medical necessity: the case of prescription drugs with abuse potential. Substance Use \& Misuse. Jul-Aug 2001;36(9-10):12751296.

52. Fountain J, Strang J, Gossop M, Farrell M, Griffiths P. Diversion of prescribed drugs by drug users in treatment: analysis of the UK market and new data from London. Addiction. Mar 2000;95(3):393-406.

53. Passik SD, Kirsh KL, Whitcomb L, Dickerson PK, Theobald DE. Pain clinicians' rankings of aberrant drug-taking behaviors. Journal of Pain \& Palliative Care Pharmacotherapy. 2002;16(4):39-49.

54. Bohnert ASB, Valenstein M, Bair MJ, et al. Association Between Opioid Prescribing Patterns and Opioid Overdose-Related Deaths. JAMA: The Journal of the American Medical Association. 2011;305(13):1315. 


\section{Appendix A: Variable Code Book}

\section{Objective 1-3}

Identifying Variables

First \& Last Name $\rightarrow$ Unique ID

Date of Birth $\rightarrow$ Age

Doctor DEA

Pharmacy DEA

\section{Life Status}

Living $=0$

Deceased $=1$

Age

= calculated from the date of birth and last fill date in the CSMP; found in the FDD as the age at death

Age Group

$18-24=0$

$25-34=1$

$35-44=2$

$45-54=3$

$55-64=4$

$\geq 65=5$

\section{Number of Doctors}

$=$ number of doctors that prescribed CDS prescriptions per subject for the 6 months prior to the last CDS prescription dispensed

\section{Doctor Shopping}

NoDrShop (<4 clincians/last 6 months) $=0$

DrShop ( $\geq 4$ clinicians/last 6 months $)=1$

Number of Pharmacies

$=$ number of pharmacies that dispensed CDS prescriptions per subject for the 6 months prior to the last CDS prescription dispensed

\section{Pharmacy Shopping}

NoPhShop (<4 pharmacies/last 6 months) $=0$

PhShop ( $\geq 4$ pharmacies/last 6 months) $=1$

\section{Date Filled}

$=$ the dates when the pharmacy dispensed the controlled drug substance prescription 
Number of Prescriptions Dispensed

$=$ the highest frequency of the number of controlled drug substance prescriptions dispensed that overlap in a 60 day window for the 6 months prior to the last controlled drug substance dispensed Number of Prescriptions Dispensed Group

1 Prescription $=0$

2 Prescriptions $=1$

3 Prescriptions $=2$

4 or more Prescriptions $=3$

Drug Name

= name of drug dispensed

Number of Different CDS Dispensed

Single CDS $=0$

2 different $C D S=1$

3 or more different $C D S=2$

\section{Objective 4}

Unique ID

\section{CDS prescription Verification}

Verified $=0$

Non-verified $=1$

Age

=the age at death

Age Group

$18-24=0$

$25-34=1$

$35-44=2$

$45-54=3$

$55-64=4$

$\geq 65=5$

Drug Name

= name of drug detected upon autopsy

Number of Different CDS Detected at Autopsy

Single CDS $=0$

2 different $\mathrm{CDS}=1$

3 or more different $C D S=2$

Gender

Male $=1$

Female $=0$ 